\title{
Ionic Liquid (1-Ethyl-3-methylimidazolium Acetate) Plasticization of Chitosan-Based Bionanocomposites
}

\author{
Pei Chen, Fengwei Xie,* Fengzai Tang, and Tony McNally* \\ Cite This: https://dx.doi.org/10.1021/acsomega.0c02418 \\ Read Online
}

ABSTRACT: The structure and properties of different biopolymer composites based on chitosan and chitosan/carboxymethyl cellulose (CMC) are governed by multiple structure-property relationships associated with different phase interactions. Plasticization of these matrices with ionic liquid 1-ethyl-3-methylimidazolium acetate $\left(\left[\mathrm{C}_{2} \mathrm{mim}\right][\mathrm{OAc}]\right)$ played a dominant role, increasing the mobility of biopolymer chains as well as ions and associated dipoles but reducing biopolymer chain interactions, crystallinity, and thermal stability. These structural changes led to higher matrix ionic conductivity, shorter electrical relaxation time, and greater matrix ductility. The inclusion of graphene oxide (GO) and reduced GO (rGO) also influenced the structure and

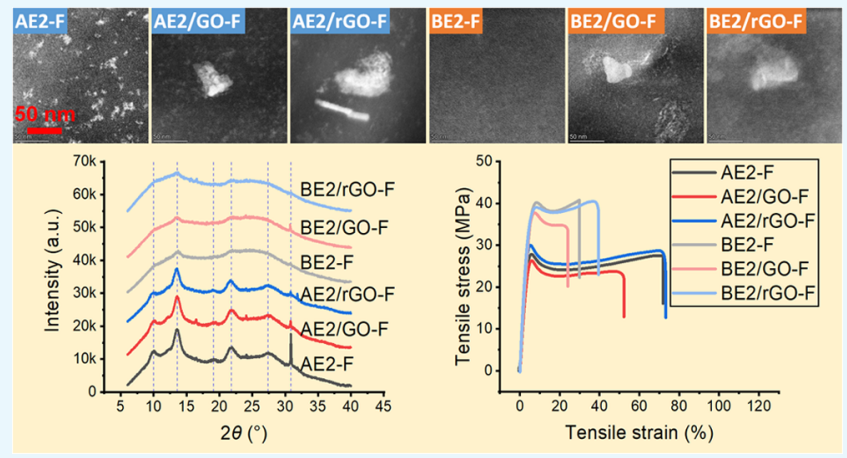
properties of these bionanocomposites by disrupting the biopolymer hydrogen bonding and/or polyelectrolyte complexation (PEC) and interacting with $\left[\mathrm{C}_{2}\right.$ mim] [OAc]. The impact of $\mathrm{GO} / \mathrm{rGO}$ was more evident for $20 \mathrm{wt} \%\left[\mathrm{C}_{2} \mathrm{mim}\right]$ [OAc], such as increased crystallinity and thermal stability of chitosan. PEC was hindered with excess $(40 \mathrm{wt} \%)\left[\mathrm{C}_{2} \mathrm{mim}\right][\mathrm{OAc}]$ added and further hindered again when rGO was included. This study shows that the structure and properties of bionanocomposites are not just determined by the surface chemistry of GO/rGO but can also be influenced by multiple interactions involving plasticizers such as ILs and additional biopolymers.

\section{INTRODUCTION}

Biopolymers, which are defined as macromolecules (including proteins, nucleic acids, and polysaccharides) formed by living organisms according to the IUPAC, have attracted much interest in materials development in recent years due to their renewability, biodegradability, and inherent functionality (e.g., antimicrobial activity of chitosan). Polymer chain interactions such as hydrogen bonding play a pivotal role in determining the structure and properties of biopolymers. A high degree of hydrogen bonding between biopolymer chains may realize drastically improved mechanical properties. ${ }^{1-3}$ Nonetheless, to assist in the processing of biopolymers and to fabricate biopolymers with increased ductility, plasticizers need to be introduced to the biopolymer formulation, which can disrupt the intrinsic hydrogen-bonding network, control the density of newly formed hydrogen bonds, and increase chain mobility, thus modifying material properties. For this purpose, ionic liquids (ILs), often referred to as "green solvents", have recently attracted great interest for processing and plasticization of biopolymers. $^{4-12}$ ILs that contain a strongly basic, hydrogen-bond-accepting anion (e.g., carboxylates or halides) are capable of disrupting the intermolecular hydrogen bonding wholly or partially in biopolymer networks. ${ }^{12}$ Moreover, the use of ILs could lead to the development of advanced biopolymer materials such as ionically conducting polymers or solid polymer electrolytes. $^{13-20}$
In this work, we investigated the effect of an IL, 1-ethyl-3methylimidazolium acetate $\left(\left[\mathrm{C}_{2} \mathrm{mim}\right][\mathrm{OAc}]\right)$, added at 20 or $40 \mathrm{wt} \%$ levels, on the structure and properties of different chitosan and chitosan/carboxymethyl cellulose (CMC) composites. $\left[\mathrm{C}_{2} \mathrm{mim}\right][\mathrm{OAc}]$ has desirable properties such as low melting point $\left(<-20{ }^{\circ} \mathrm{C}\right)$, viscosity $\left(10 \mathrm{mPa} \cdot \mathrm{s}\right.$ at $\left.80{ }^{\circ} \mathrm{C}\right)$, toxicity $\left(\mathrm{LD}_{50}>2000 \mathrm{mg} \cdot \mathrm{kg}^{-1}\right)$, corrosiveness, and adequate biodegradability, ${ }^{21}$ which make this IL suitable for processing of biopolymers with minimal impact on health and the environment.

In composites, the chitosan polycation and the CMC polyanion are expected to participate in polyelectrolyte complexation (PEC) through electrostatic attraction as a type of dynamic bonding. The advantages of PEC have been recently demonstrated in the development of various advanced biopolymer materials with superior properties to that any single biopolymer can achieve, such as mechanical ${ }^{22-24}$ and

Received: $\quad$ May 22, 2020

Accepted: July 8, 2020 

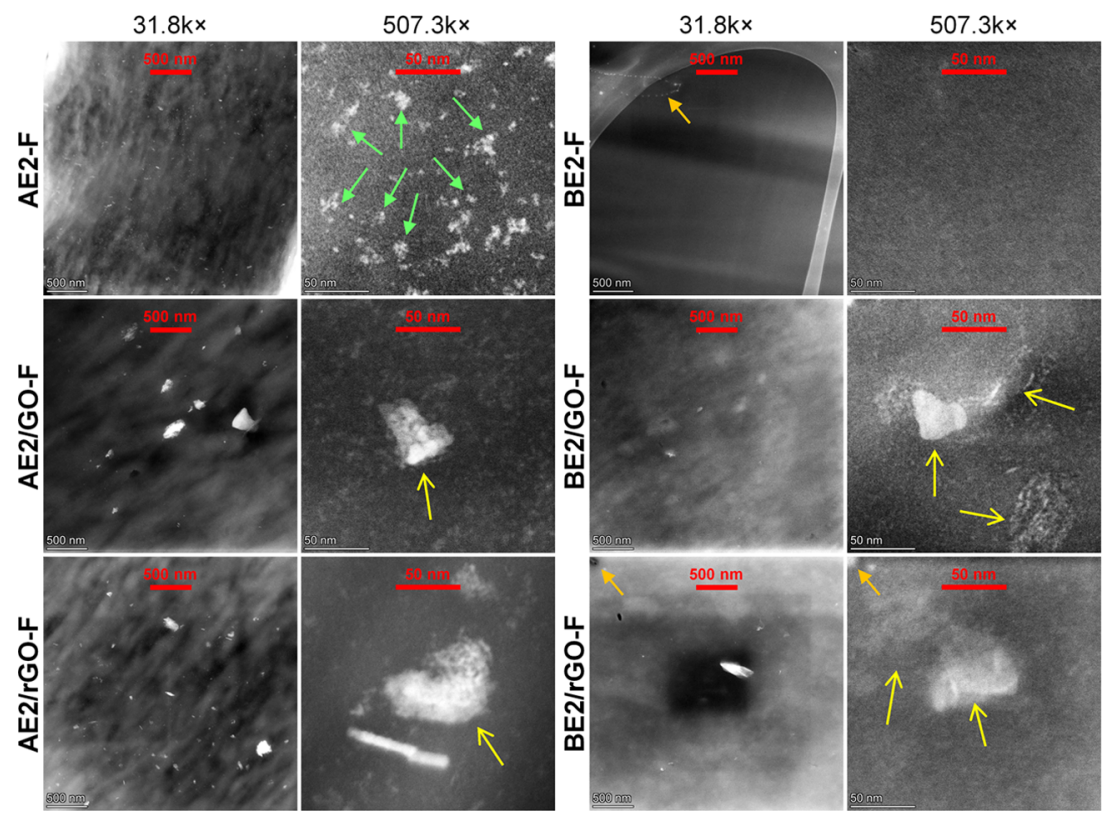

Figure 1. Scanning transmission electron microscopy high-angle annular dark-field imaging (STEM-HAADF) images of the different biopolymer and bionanocomposite films. The green arrows indicate nondispersed particulate features (chitosan structure); the yellow arrows indicate large flocculent substances (GO or rGO nanosheets not fully exfoliated); the dotted features at the top left of the images (examples indicated by the orange arrows) were STEM beam-induced damages.

barrier properties, ${ }^{25}$ hydrolytic stability, ${ }^{26}$ and cell adhesiveness. $^{27}$

The nanofillers used, graphene oxide (GO) and reduced graphene oxide ( $\mathrm{rGO}$ ), have different concentrations of oxygen-containing groups (e.g., $-\mathrm{COOH}$ and $-\mathrm{OH}$ ) and negative charges ${ }^{28}$ and, thus, should have different degrees of hydrogen-bonding and electrostatic interactions with biopolymers. Graphene has drawn great attention due to its exceptional thermal conductivity, mechanical properties, and electronic transport properties. ${ }^{29}$ Moreover, two-dimensional (2D) graphenic nanomaterials have also demonstrated antimicrobial activity. ${ }^{30-33}$ Thus, the incorporation of GO and rGO into biopolymer matrices (resulting in bionanocomposites) is expected to enhance the properties and functionality of the biopolymers for possible wider application.

In this research, effective mixing of the different components (i.e., chitosan, CMC, GO/rGO, and ILs) was achieved by thermomechanical kneading of the condensed material systems at high viscosity. We hypothesize that the structure and properties of the dual bionanocomposites are not wholly determined by the surface chemistry of the $2 \mathrm{D}$ carbon nanomaterial. How $\left[\mathrm{C}_{2} \mathrm{mim}\right][\mathrm{OAc}]$ influences hydrogenbonding and electrostatic interactions among the different components and, subsequently, the structure and properties of the resulting composites have not been widely reported before.

\section{RESULTS AND DISCUSSION}

Morphology. Figure 1 shows the nanoscale structures of the different formulations examined by scanning transmission electron microscopy (STEM). All of the chitosan-based (A) samples at a high magnification $(507 \mathrm{k} \times)$ showed some particulate features, possibly associated with chitosan structures not destroyed by processing or the formation of new crystals (further discussed in XRD results). AE2/GO-F and $\mathrm{AE} 2 / \mathrm{rGO}-\mathrm{F}$ (the chitosan matrix plasticized by $20 \mathrm{wt} \%$ $\left[\mathrm{C}_{2} \mathrm{mim}\right][\mathrm{OAc}]$ and included with $\mathrm{GO}$ or $\mathrm{rGO}$ ) displayed additional larger features, most probably agglomerations of $\mathrm{GO} / \mathrm{rGO}$. As these agglomerates were small in number and scattered very sparsely, it was likely that more finely dispersed, few-layer $\mathrm{GO} / \mathrm{rGO}$ nanosheets were also present but were not readily visible under STEM. In contrast, BE2-F (the chitosan/ CMC matrix plasticized by $20 \mathrm{wt} \%\left[\mathrm{C}_{2} \mathrm{mim}\right][\mathrm{OAc}]$ without nanofiller) exhibited a clear morphology without particulate features seen for the A-samples. In comparison, the STEM images of $\mathrm{BE} 2 / \mathrm{GO}-\mathrm{F}$ and $\mathrm{BE} 2 / \mathrm{rGO}-\mathrm{F}$ (the chitosan/CMC matrix plasticized by $20 \mathrm{wt} \%\left[\mathrm{C}_{2} \mathrm{mim}\right][\mathrm{OAc}]$ and included with $\mathrm{GO}$ or $\mathrm{rGO}$ ) only showed some flocculent substances clearly observable at a high magnification $(507 \mathrm{k} \times)$, indicating the presence of $\mathrm{GO}$ or rGO.

The oxygen-containing groups (e.g., $-\mathrm{COOH}$ and $-\mathrm{OH}$ ) and negative charges resulting from ionization of carboxylic acid and phenolic hydroxyl groups on the GO nanosheets can interact effectively with the chitosan polycation through hydrogen bonding and electrostatic attraction. ${ }^{28}$ Moreover, different studies ${ }^{28,34,35}$ have shown the excellent dispersion of GO in chitosan materials. Here, our STEM images indicated similar morphologies for the samples containing GO and $\mathrm{rGO}$, irrespective of matrix type, demonstrating the efficient dispersion of $\mathrm{GO} / \mathrm{rGO}$ in both matrices enabled by thermomechanical mixing.

Crystalline Structure. Figure 2 shows the X-ray diffraction (XRD) curves for the different films. As discussed previously, ${ }^{26}$ these processed samples should contain predominantly a recrystallized structure, with their XRD patterns entirely different from that for unprocessed chitosan. With 40 wt \% $\left[\mathrm{C}_{2} \mathrm{mim}\right][\mathrm{OAc}]$, the peak intensities (especially the one at $13.6^{\circ}$ ) were moderately reduced, indicating that a higher IL content may have hindered chitosan recrystallization. Moreover, for the A-matrix containing either 20 or 40 wt \% $\left[\mathrm{C}_{2} \mathrm{mim}\right][\mathrm{OAc}]$, addition of $\mathrm{rGO}$ led to less intense XRD peaks, indicating rGO might have suppressed chitosan recrystallization. However, no such effect was apparent for 

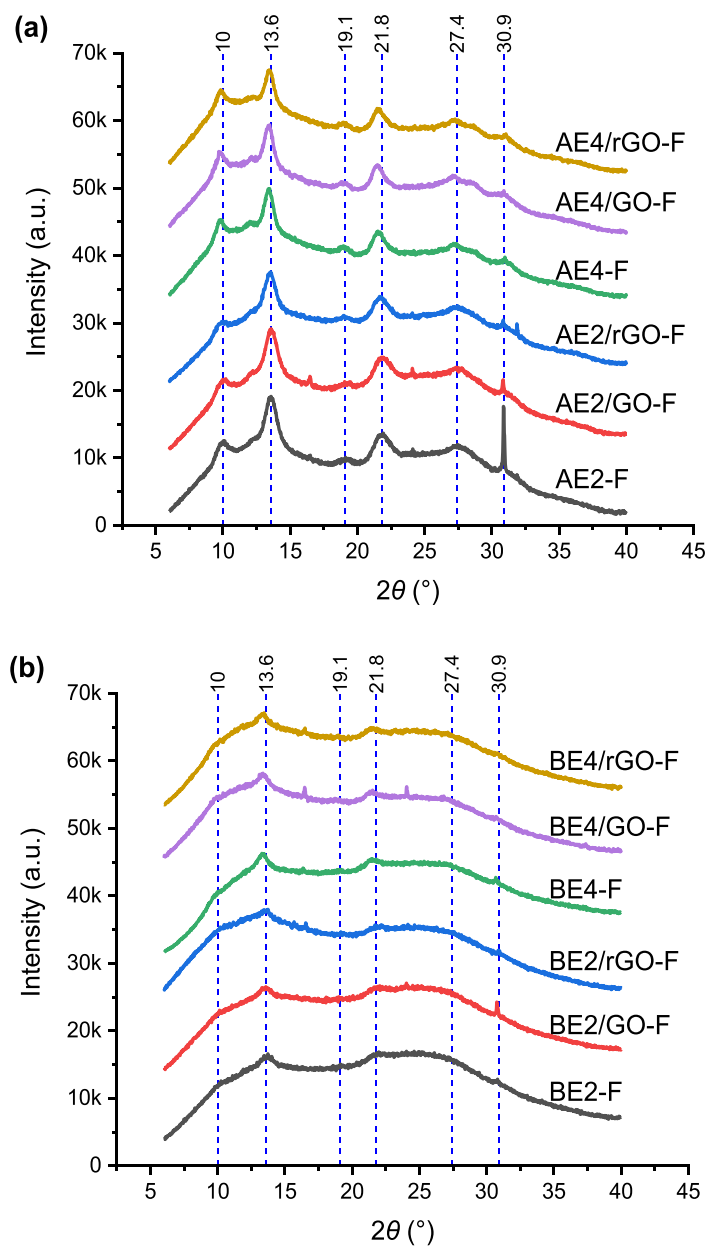

Figure 2. X-ray diffractograms for the different biopolymer and bionanocomposite films: (a) chitosan matrix and (b) chitosan/CMC matrix. The reference lines indicate characteristic peaks for AE2-F.

GO. In this regard, rGO, being less hydrophilic than chitosan, may have interfered with chitosan chain interactions and recrystallization.

The B-series of materials also showed similar peaks to the Aseries, but they were much less intense. The characteristic peak at $23.3^{\circ}$ ascribed to the (110) lattice plane of the cellulose II crystalline structure for unprocessed $\mathrm{CMC}^{26}$ was absent. This indicates that while processing had predominantly destroyed the original crystalline structures of both biopolymers, only the chitosan in the B-samples had undergone some degree of recrystallization. The recrystallized chitosan structure was formed with the assistance of $\left[\mathrm{C}_{2} \mathrm{mim}\right][\mathrm{OAc}]$, as a predominantly amorphous material was obtained without plasticizer. $^{36}$ The effect of $\left[\mathrm{C}_{2} \mathrm{mim}\right][\mathrm{OAc}]$ can also be confirmed by the slightly increased peak intensities (especially at $10,13.6$, and $21.8^{\circ}$ ) with increasing IL content from 20 to 40 wt \%. Compared with BE2-F, BE2/GO-F displayed almost the same peak intensities while $\mathrm{BE} 2 / \mathrm{rGO}-\mathrm{F}$ showed more intense peaks at 10 and $13.6^{\circ}$. Compared with BE4-F, both $\mathrm{BE} 4 / \mathrm{GO}-\mathrm{F}$ and $\mathrm{BE} 4 / \mathrm{rGO}-\mathrm{F}$ exhibited greater peak intensities at 10 and $13.6^{\circ}$. This indicates that GO or rGO might have facilitated chitosan recrystallization.

Molecular Interactions. Figure 3a shows that the Fourier transform infrared (FTIR) spectra of the A-samples with $20 \mathrm{wt}$ $\%\left[\mathrm{C}_{2} \mathrm{mim}\right][\mathrm{OAc}]$ were almost the same as that of A-F (processed chitosan film without plasticizer, reported pre-
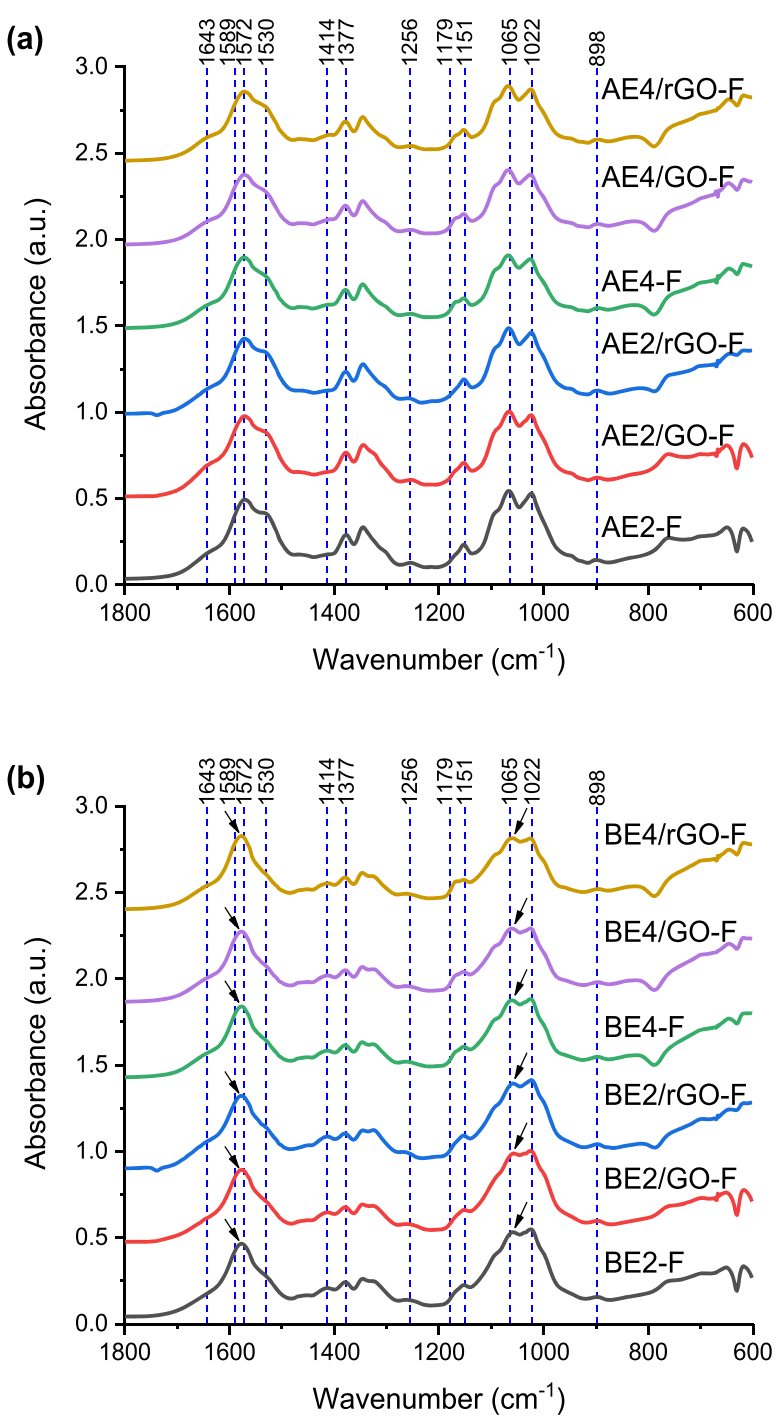

Figure 3. FTIR spectra of the different biopolymer and bionanocomposite films: (a) chitosan matrix; (b) chitosan/CMC matrix. The reference lines indicate characteristic bands for unprocessed CMC $\left(1589,1414\right.$, and $\left.1022 \mathrm{~cm}^{-1}\right),{ }^{26}$ unprocessed chitosan $(1643,1572,1530,1377,1256,1151,1065,1022$, and 898 $\left.\mathrm{cm}^{-1}\right),{ }^{41}$ and $\left[\mathrm{C}_{2} \mathrm{mim}\right][\mathrm{OAc}]\left(1179 \mathrm{~cm}^{-1}\right)$ (see Figure S2a). The arrows indicate shifts in peak position.

viously). ${ }^{26}$ The FTIR spectra of the A-samples with 20 and 40 wt $\%\left[\mathrm{C}_{2} \mathrm{mim}\right][\mathrm{OAc}]$ were very similar. The only difference was that the peak at $1179 \mathrm{~cm}^{-1}$, derived from the imidazolium ring of the IL (see Figure S2a), was more pronounced (but with a red shift to $1169 \mathrm{~cm}^{-1}$ ). The red shift of this peak reflects that a lower vibration energy is needed for the imidazolium ring when the IL interacted with the biopolymers. ${ }^{37}$ Specifically, it is the acetate anion that interacts with biopolymer hydroxyl groups leading to dissolution or plasticization, ${ }^{38-40}$ the interaction between the IL imidazolium cation and the acetate group was weakened because of the interactions between the acetate group and the biopolymer polar groups. No obvious shifts in the peaks for the biopolymers can be observed with addition of $\left[\mathrm{C}_{2} \mathrm{mim}\right][\mathrm{OAc}]$. Moreover, the inclusion of GO or rGO did not cause any obvious changes to the FTIR bands, most likely due to the low GO or rGO content. 
(a)

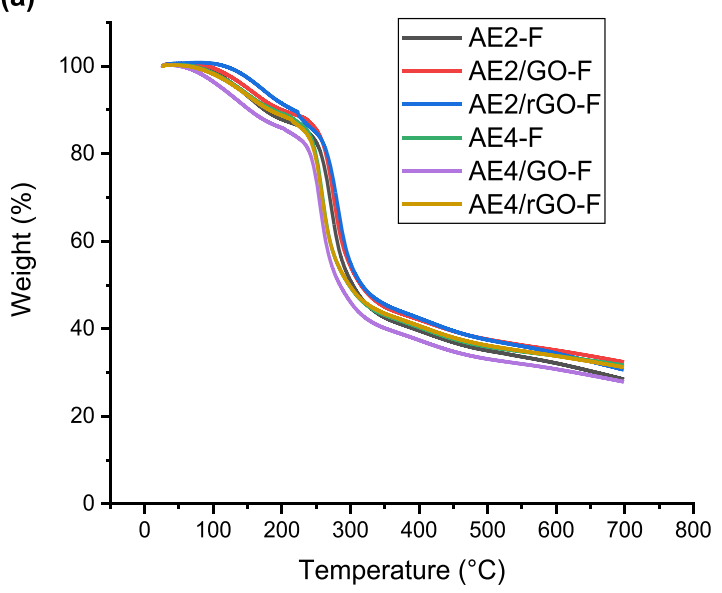

(c)

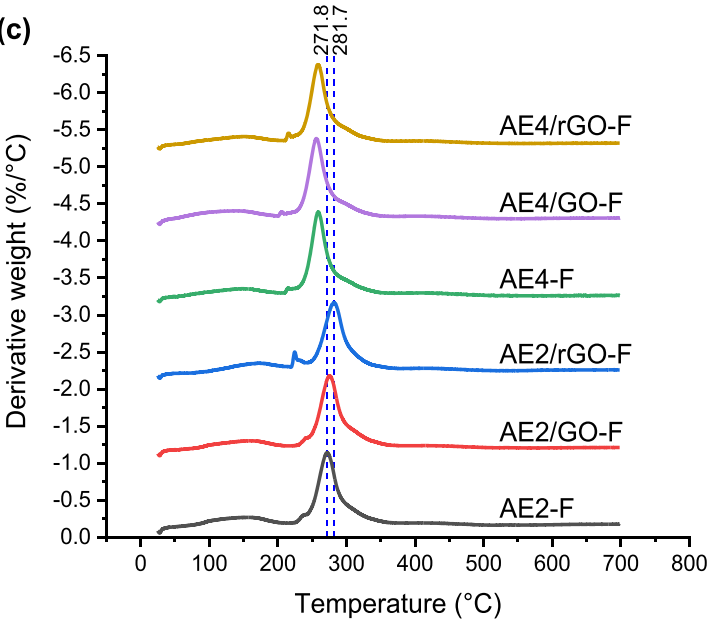

(b)

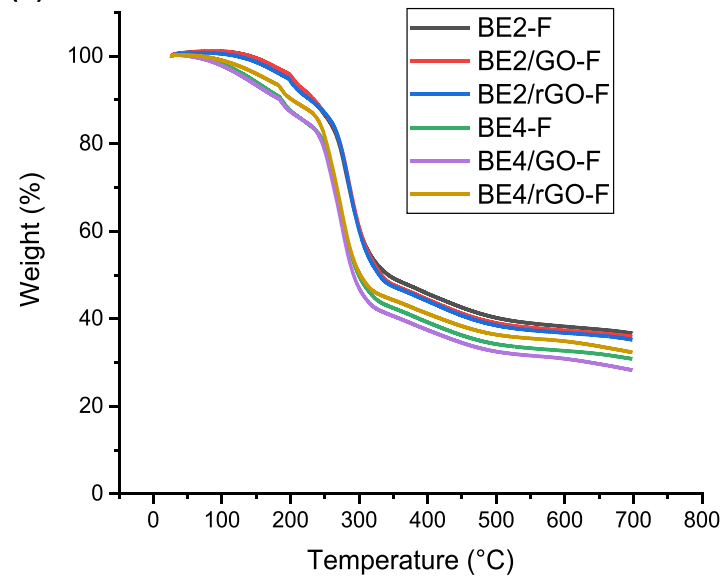

(d)

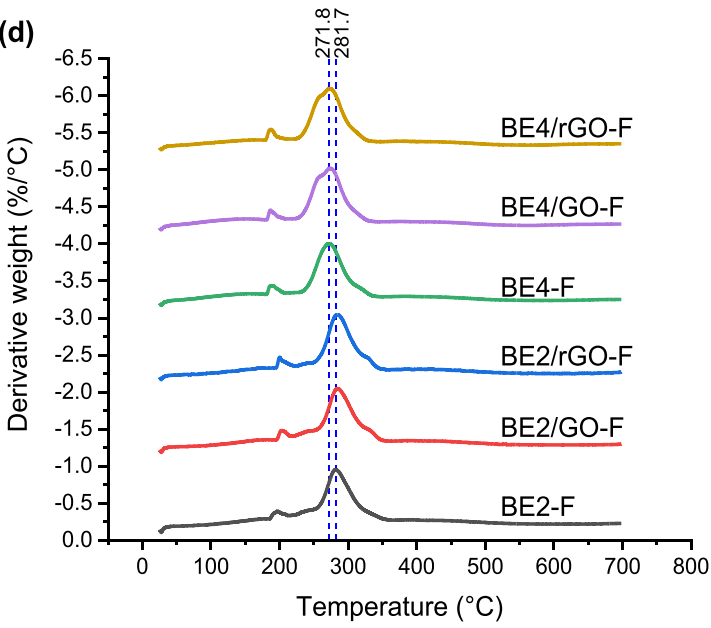

Figure 4. Weight percentage $v$ s temperature curves ((a) chitosan matrix; (b) chitosan/CMC matrix) and derivative weight $v s$ temperature curves ( (c) chitosan matrix; (d) chitosan/CMC matrix) for the different biopolymer and bionanocomposite films. The reference lines indicate the major peak temperatures of BE2-F and AE2-F, respectively.

The B-series displayed FTIR spectra mostly similar to those for the A-series, although there were some changes in peak intensities. Derived from the CMC in the matrix, there was an additional reflection at $1414 \mathrm{~cm}^{-1}$ aligned to the asymmetric stretching vibration of carboxylate ions. The characteristic bands for $\mathrm{CMC}$ at $1055 \mathrm{~cm}^{-1}$ (C-O stretching vibration of ether groups) and $1589 \mathrm{~cm}^{-1}$ (symmetric stretching vibration of carboxylate ions $)^{42-45}$ may be overlapped by chitosan signals. Furthermore, there was a blue shift of the band originally at $1572 \mathrm{~cm}^{-1}(\mathrm{~N}-\mathrm{H}$ bending from amine and amide II) and a red shift of the band originally at $1065 \mathrm{~cm}^{-1}$ (asymmetric $\mathrm{C}-\mathrm{O}-\mathrm{C}$ stretching in glycosidic linkage). ${ }^{46-48}$ These shifts in band position confirm strong molecular interactions between the two complexed biopolymers. With a higher $\left[\mathrm{C}_{2} \mathrm{mim}\right][\mathrm{OAc}]$ content, the characteristic peak originally at $1179 \mathrm{~cm}^{-1}$ (shifted to $1169 \mathrm{~cm}^{-1}$ ) became more intense, but no further band shifts for the biopolymers were observed. For the B-series, the addition of GO or rGO did not result in any discernible changes in the FTIR bands, perhaps not surprising given the $\mathrm{GO} / \mathrm{rGO}$ loading was just 0.75 wt \%.

Thermal Stability. Using thermogravimetric analysis (TGA), plots of weight percentage (Figure $4 a, b$ ) and derivative weight (Figure $4 c, d$ ) as a function of temperature for the different films were obtained. For all of the samples, there was a moderate weight loss before $200{ }^{\circ} \mathrm{C}$, which could be mainly due to moisture loss. It can be seen from Figure $4 \mathrm{a}, \mathrm{b}$ that among the A-series of samples, during this initial stage, AE2/ rGO-F had the least weight loss, whereas AE4/GO-F had the most weight loss. Among the B-series of samples, those containing $40 \mathrm{wt} \%\left[\mathrm{C}_{2} \mathrm{mim}\right][\mathrm{OAc}]$ experienced a greater weight loss than those containing $20 \mathrm{wt} \%\left[\mathrm{C}_{2} \mathrm{mim}\right][\mathrm{OAc}]$ before $200{ }^{\circ} \mathrm{C}$. These results indicate that a higher IL content led to a higher moisture content in the samples, which could be associated with the high hydrophobicity of the IL. GO and rGO, with different degrees of hydrophilicity/hydrophobicity, could also influence the moisture content in the samples.

Figure 4c,d shows that, for AE2-F, a shoulder process evolved at about $237^{\circ} \mathrm{C}$, due to the initial depolymerization of chitosan. This initial thermal decomposition event for thermomechanically processed chitosan has also been observed in previous studies. ${ }^{26,36,49-51}$ The biggest transition occurred between 225 and $365{ }^{\circ} \mathrm{C}$, undoubtedly attributed to the degradation of the biopolymer. The peak temperature $\left(T_{\mathrm{d}}\right.$, when the weight loss occurs at the maximum rate) of this major weight loss was $272{ }^{\circ} \mathrm{C}$, much lower than that of A-F $\left(297{ }^{\circ} \mathrm{C}\right)$, indicating that plasticization by $\left[\mathrm{C}_{2} \mathrm{mim}\right][\mathrm{OAc}]$ resulted in a decrease in the thermal stability of chitosan. Similarly, earlier studies ${ }^{4,6}$ showed that $\left[\mathrm{C}_{2} \mathrm{mim}\right][\mathrm{OAc}]$ as a 
plasticizer reduced the thermal stability of plasticized starch films. $\left[\mathrm{C}_{2} \mathrm{mim}\right][\mathrm{OAc}]$ had $T_{\mathrm{d}}=252{ }^{\circ} \mathrm{C}$ (Figure S2b), which was much lower than that of unprocessed chitosan $\left(296^{\circ} \mathrm{C}\right) .^{41}$ The lower thermal stability of acetate ILs compared to ILs containing other anions like $\left[\mathrm{Cl}^{-}\right]$has been well documented. ${ }^{52}$ The radicals generated from the earlier thermal decomposition of the acetate anion (and the imidazolium cation) could possibly accelerate the chain scission of the biopolymer with increasing temperature. It is also possible that the IL promoted biopolymer chain degradation during thermomechanical processing. $8,9,11$ The reduced thermal stability of biopolymers treated with ILs has been noted before. ${ }^{4,53,54}$ With a higher $\left[\mathrm{C}_{2} \mathrm{mim}\right][\mathrm{OAc}]$ content, AE4-F displayed an even lower $T_{\mathrm{d}}$ value $\left(259{ }^{\circ} \mathrm{C}\right)$, further testifying the effect the IL has in reducing the biopolymer thermal stability.

Compared to AE2-F, AE2/GO-F exhibited a slightly increased $T_{\mathrm{d}}$ value $\left(276{ }^{\circ} \mathrm{C}\right)$ and $\mathrm{AE} 2 / \mathrm{rGO}-\mathrm{F}$ displayed an even higher $T_{\mathrm{d}}$ value $\left(282{ }^{\circ} \mathrm{C}\right)$. In other words, both $\mathrm{GO}$ and rGO were effective at enhancing the thermal stability of chitosan. According to Stankovich et al., ${ }^{55} \mathrm{GO}$ is relatively thermally unstable with the major mass loss occurring at about $200{ }^{\circ} \mathrm{C}$ presumably due to pyrolysis of the labile oxygencontaining functional groups, whereas rGO is more thermally stable. In line with this, our recent research ${ }^{36}$ indicated that addition of GO decreased the $T_{\mathrm{d}}$ value of A-F (from 297 to $289{ }^{\circ} \mathrm{C}$ ), whereas rGO addition resulted in increased $T_{\mathrm{d}}$ (to $307{ }^{\circ} \mathrm{C}$ ). Here, the interaction between chitosan and $\mathrm{GO}$ possibly competed with that between chitosan and the acetate group of the IL, reducing the effect of $[\mathrm{OAc}]^{-}$and contributing to the decrease in the thermal stability of chitosan.

Compared to that of AE4-F $\left(259^{\circ} \mathrm{C}\right)$, the $T_{\mathrm{d}}$ value of AE4/ rGO-F was unchanged, whereas the $T_{\mathrm{d}}$ value of AE4/GO-F was slightly reduced to $256{ }^{\circ} \mathrm{C}$. It is possible that the plasticizer at higher content dominates the interaction with chitosan, while the interactions between chitosan and GO became insignificant. In this way, the low thermal stability of GO also led to reduced thermal stability of the whole composite matrix. Similarly, the positive effect of $\mathrm{rGO}$ at a higher $\left[\mathrm{C}_{2} \mathrm{mim}\right][\mathrm{OAc}]$ content became negligible.

BE2-F had $T_{\mathrm{d}}=282{ }^{\circ} \mathrm{C}$. Before the major peak, there was a small thermal decomposition event between 184 and $214{ }^{\circ} \mathrm{C}$ ascribed to the initial decomposition of the biopolymers. Overlapped with the main peak, there is another peak signifying an event at a higher temperature between 320 and $358{ }^{\circ} \mathrm{C}$, associated with the polyelectrolyte complexed structure that was more resistant to thermal decomposition. Our previous work ${ }^{26}$ showed that the major weight loss of thermomechanically processed chitosan/CMC without plasticizer (B-F) was composed of two pronounced overlapping peaks, the stronger one at $273{ }^{\circ} \mathrm{C}\left(T_{\mathrm{d}}\right)$ and the weaker one at $304{ }^{\circ} \mathrm{C}$. In comparison, BE2-F displayed a more-defined peak. The $T_{\mathrm{d}}$ value of BE2-F was also higher than that of AE2-F. Thus, the addition of $\left[\mathrm{C}_{2} \mathrm{mim}\right][\mathrm{OAc}]$ enhanced the thermal stability of the B-matrix possibly by assisting biopolymer chain mobility and then interactions between the two biopolymers.

Compared to BE2-F, BE2/GO-F and BE2/rGO-F had slightly higher $T_{\mathrm{d}}$ values $\left(285^{\circ} \mathrm{C}\right.$ and $\left.284^{\circ} \mathrm{C}\right)$. The $T_{\mathrm{d}}$ value of BE4-F $\left(272{ }^{\circ} \mathrm{C}\right)$ was less than that of BE2-F. Therefore, it is possible that $\mathrm{PEC}$ might become less effective with excess $\left[\mathrm{C}_{2} \mathrm{mim}\right][\mathrm{OAc}]$. BE4/GO-F and BE4/rGO-F had $T_{\mathrm{d}}$ values similar to that of BE4-F. Nonetheless, for these two samples, there seemed to be an additional, overlapping peak at about 258-259 ${ }^{\circ} \mathrm{C}$, which could be due to CMC. Likely, the combined effects of inclusion of $\mathrm{GO}$ or $\mathrm{rGO}$ and a high $\left[\mathrm{C}_{2} \mathrm{mim}\right][\mathrm{OAc}]$ content resulted in a lower degree of PEC and hydrogen bonding between chitosan and CMC so that the decomposition peak for CMC became more pronounced.

Molecular Relaxations. Figure 5 shows plots of loss tangent $(\tan \delta)$ as a function of temperature for the films

(a)

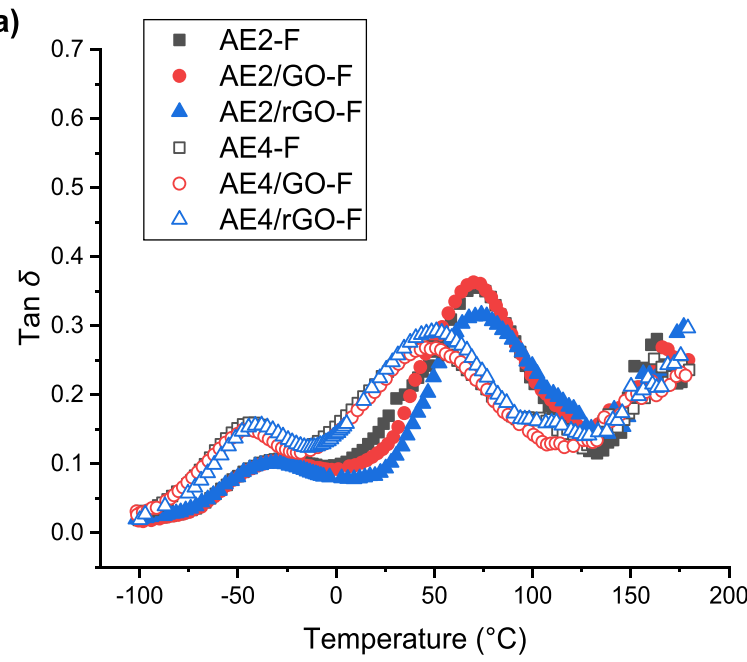

(b)

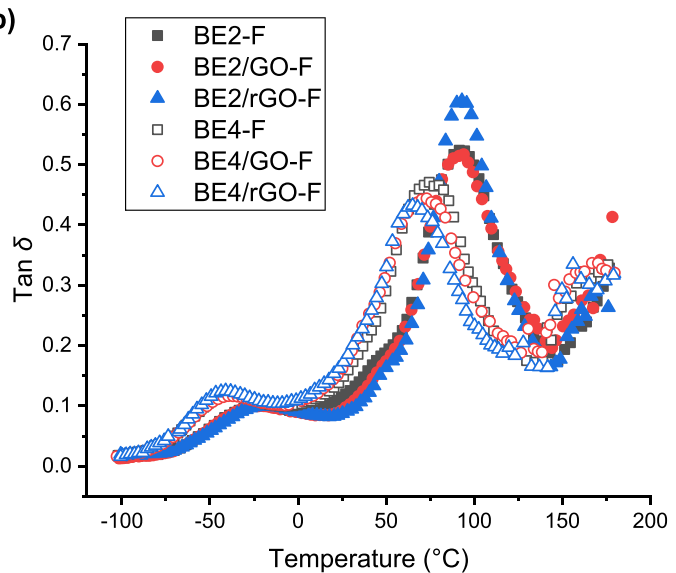

Figure 5. Damping $(\tan \delta)$ as a function of temperature for the different biopolymer and bionanocomposite films: (a) chitosan matrix; (b) chitosan/CMC matrix.

measured by dynamical mechanical thermal analysis (DMTA). All of the samples displayed two transitions, one at a lower temperature associated with a $\beta$-relaxation attributed to the motions of the side chains or lateral groups of chitosan and a much more prominent one at a higher temperature associated with the $\alpha$-transition (glass transition) of chitosan. ${ }^{56,57}$ For AE2-F, the peak temperatures of the $\beta$-transition $\left(T_{\beta}\right)$ and $\alpha$ transition $\left(T_{\alpha}\right)$ were about -28 and $73{ }^{\circ} \mathrm{C}$, respectively. The $T_{\beta}$ and $T_{\alpha}$ values of AE2-F were much lower than those of A-F $\left(-47\right.$ and $119{ }^{\circ} \mathrm{C}$, respectively), ${ }^{26}$ suggesting that $\left[\mathrm{C}_{2} \mathrm{mim}\right]$ [OAc] readily plasticized the chitosan and increased chitosan chain mobility. AE2/GO-F and AE2/rGO-F displayed very similar $\tan \delta$ profiles to that of AE2-F. In these samples, the chain mobility could be mainly determined by the IL, whereas the effect of $\mathrm{GO}$ or $\mathrm{rGO}$ was minor. 

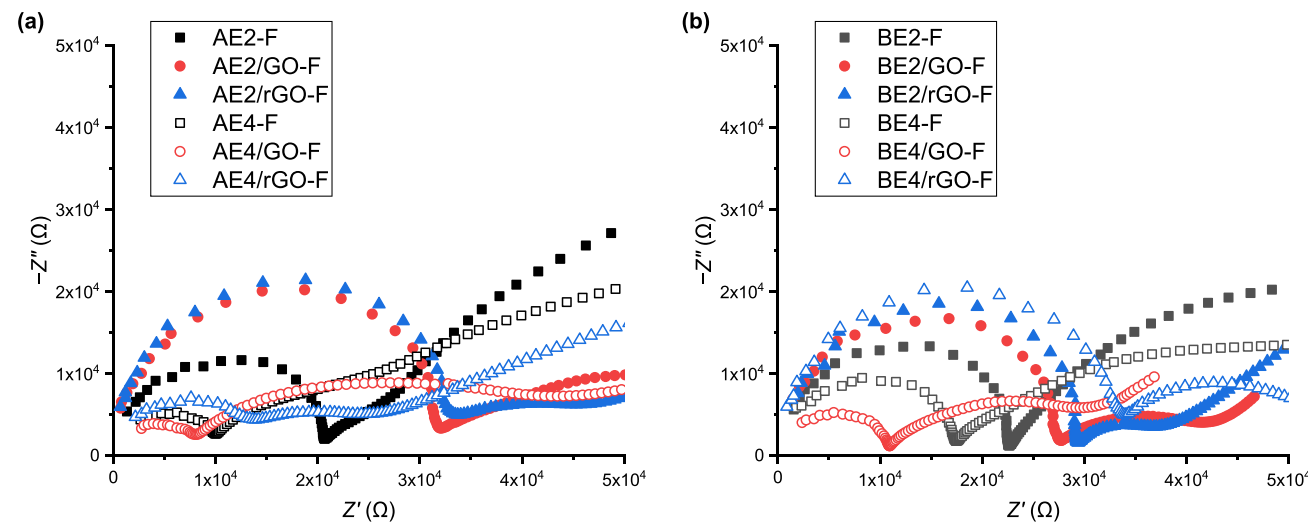

(c)

(d)
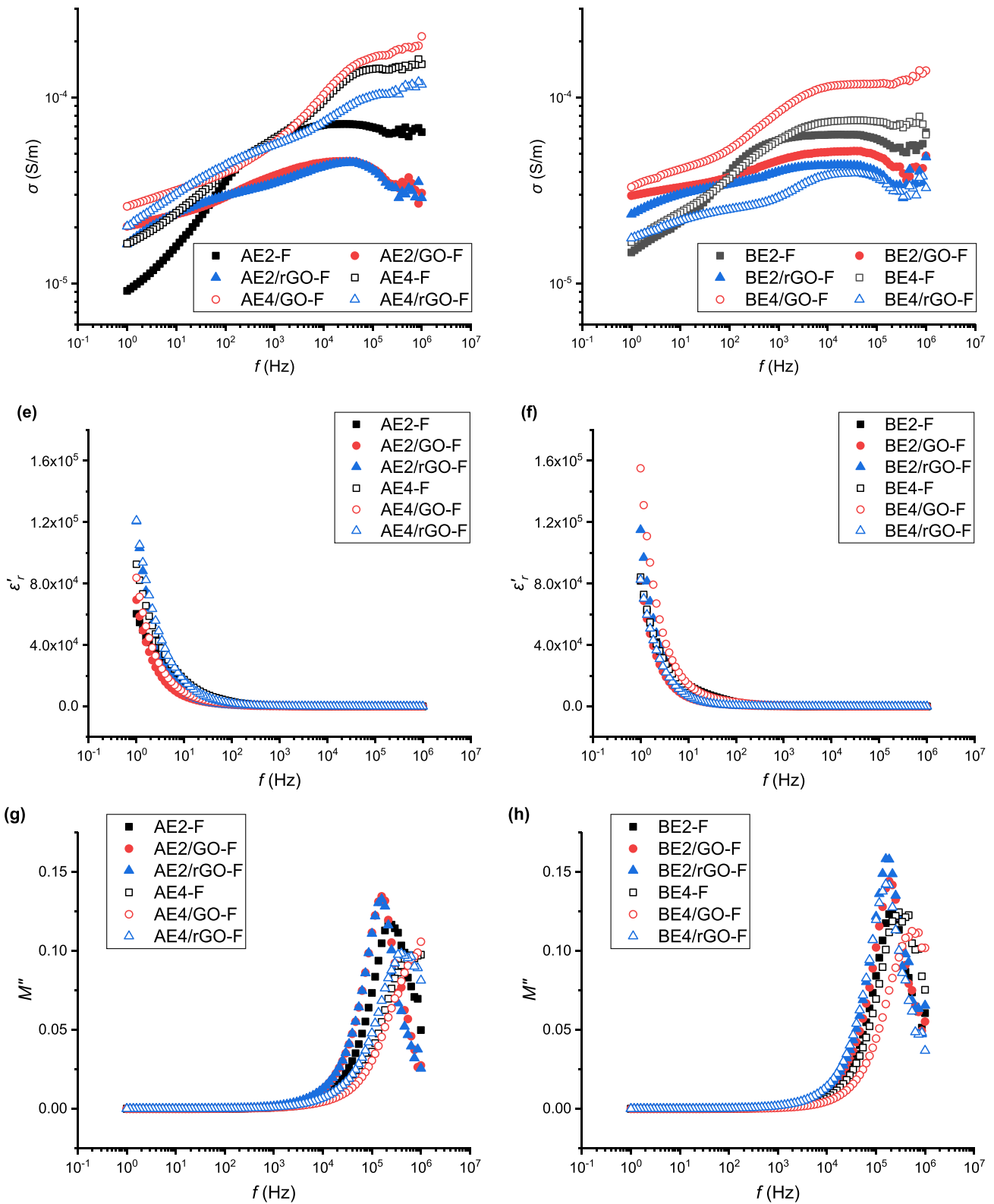

Figure 6. EIS results of the different biopolymer and bionanocomposite films: (a, b) Nyquist plot of impedance; (c, d) alternating current (AC) conductivity $(\sigma)$; (e, f) real relative permittivity $\left(\varepsilon_{\mathrm{r}}^{\prime}\right)$; and $(\mathrm{g}, \mathrm{h})$ imaginary electric modulus $\left(M^{\prime \prime}\right)$.

With a higher $(40 \mathrm{wt} \%)\left[\mathrm{C}_{2} \mathrm{mim}\right][\mathrm{OAc}]$ content, both $\mathrm{T}_{\beta}$ and $T_{\alpha}$ were significantly reduced. AE4-F had $T_{\beta}=-42{ }^{\circ} \mathrm{C}$ and $T_{\alpha}=46^{\circ} \mathrm{C}$. AE4/GO-F had similar $T_{\beta}$ and $T_{\alpha}$ values to those of AE4-F while the $T_{\alpha}$ value of AE4/rGO-F was slightly higher $\left(51{ }^{\circ} \mathrm{C}\right)$, possibly due to the confinement effect of $\mathrm{rGO}$ on chitosan chain mobility. 
BE2-F had $T_{\beta}=-23{ }^{\circ} \mathrm{C}$ and $T_{\alpha}=91{ }^{\circ} \mathrm{C}$, which appeared not to be changed by addition of GO or rGO. These values were higher than those for the A-samples with $20 \%$ $\left[\mathrm{C}_{2} \mathrm{mim}\right][\mathrm{OAc}]$, suggesting that $\mathrm{PEC}$ restricted the biopolymer chain mobility. BE4-F had $T_{\beta}=-38{ }^{\circ} \mathrm{C}$ and $T_{\alpha}=74{ }^{\circ} \mathrm{C}$, with the greater $\left[\mathrm{C}_{2} \mathrm{mim}\right][\mathrm{OAc}]$ content resulting in a higher chain mobility. Interestingly, inclusion of $\mathrm{GO}$ or $\mathrm{rGO}$ to the plasticized B-series materials further reduced the relaxation temperatures. BE2/GO-F had $T_{\beta}=-38{ }^{\circ} \mathrm{C}$ and $T_{\alpha}=72{ }^{\circ} \mathrm{C}$, and $\mathrm{BE} 2 / \mathrm{rGO}-\mathrm{F}$ had $\mathrm{T}_{\beta}=-41^{\circ} \mathrm{C}$ and $T_{\alpha}=66^{\circ} \mathrm{C}$. It may be that $\mathrm{rGO}$ interfered with PEC between the two biopolymers, leading to increased chain mobility.

Electrochemical Impedance Spectroscopy (EIS). Figure 6a,b shows the Nyquist plots of $Z^{\prime \prime}$ vs $Z^{\prime}$, consisting of a half semicircle at high frequencies $(f)$ characteristic of a combination of bulk resistance and bulk capacitance in parallel. $^{58}$ A larger semicircular is indicative of greater bulk resistance. Based on these plots, the values of bulk resistance $\left(R_{\mathrm{b}}\right)$ and ionic conductivity $\left(\sigma_{\mathrm{dc}}\right)^{58}$ calculated are listed in Table S1. Overall, $\sigma_{\mathrm{dc}}$ was strongly affected by the $\left[\mathrm{C}_{2} \mathrm{mim}\right]-$ [OAc] content and GO or rGO addition. The highest $\sigma_{\mathrm{dc}}$ value was displayed by the samples with 40 wt $\%\left[\mathrm{C}_{2} \mathrm{mim}\right][\mathrm{OAc}]$. While electrical conductivity in polymer systems is determined by electrical charges (ions and dipoles), $\left[\mathrm{C}_{2} \mathrm{mim}\right][\mathrm{OAc}]$ as a salt can also play an important role here. ${ }^{59}$ The $\sigma_{\mathrm{dc}}$ value of AE4-F $\left((13.33 \pm 4.26) \times 10^{5} \mathrm{~S} \cdot \mathrm{m}^{-1}\right)$ was higher than that of BE4-F $\left((7.30 \pm 2.91) \times 10^{5} \mathrm{~S} \cdot \mathrm{m}^{-1}\right)$, as expected, as PEC could negatively influence ionic conductivity. Addition of GO to AE4-F or BE4-F resulted in an even higher $\sigma_{\mathrm{dc}}$ (e.g., (17.77 \pm $0.72) \times 10^{5} \mathrm{~S} \cdot \mathrm{m}^{-1}$ for AE4/GO-F), while $\mathrm{rGO}$ led to a reduced $\sigma_{\mathrm{dc}}\left(\right.$ e.g., $(3.70 \pm 0.69) \times 10^{5} \mathrm{~S} \cdot \mathrm{m}^{-1}$ for BE4/rGO-F $)$. Given this, it is possible that $\mathrm{GO}$, by interaction with the biopolymer, reduced the interactions between $\left[\mathrm{C}_{2} \mathrm{mim}\right][\mathrm{OAc}]$ and the biopolymer, leading to more free IL ions available for conduction. In contrast, rGO disrupts PEC and/or hydrogen bonding between biopolymer chains, increasing the chances the IL interacts with the biopolymer, reducing the concentration of free IL ions. When the IL content is low (20 wt \%), the interaction between the IL and GO predominates, which could alter the conductivity.

Figure $6 c, d$ shows that for all of the samples, AC conductivity $(\sigma)$ increased with $f$, typical behavior of an insulating material (i.e., a dielectric). Low $\sigma$ at low $f$ results from the accumulation of charged species at the electrodeelectrolyte interface and, thus, less mobile ions in the bulk material. ${ }^{60}$ AE2-F had particularly low $\sigma$ values at low $f$, but $\sigma$ increased sharply at higher $f$. In contrast, for AE2/GO-F and $\mathrm{AE} 2 / \mathrm{rGO}-\mathrm{F}$, the $\sigma$ values at low $f$ were higher and $\sigma$ was less dependent on $f$. All of the A-samples with $40 \%\left[\mathrm{C}_{2} \mathrm{mim}\right][\mathrm{OAc}]$ had high $\sigma$ values across the whole $f$ range, due to more mobile ions in the systems. While the B-samples with $20 \%$ $\left[\mathrm{C}_{2} \mathrm{mim}\right][\mathrm{OAc}]$ displayed similar behavior, a higher IL content (40\%) did not significantly increase $\sigma$. Also, the height of the $\sigma$ curve was largely influenced by GO or rGO, in agreement with the discussion on $\sigma_{\mathrm{dc}}$ above.

Figure $6 \mathrm{e}, \mathrm{f}$ shows that for all samples, the real relative permittivity $\left(\varepsilon^{\prime}\right)$ abruptly increased with decreasing $f$, attributable to electrode polarization and space charge effects (dipole moment). ${ }^{61,62}$ Among the different samples, those containing rGO exhibited the highest $\varepsilon^{\prime}{ }_{r}$ at low $f$. In this regard, the relatively more electrically conducting rGO might assist in the accumulation of mobile ions. Moreover, all of the samples had impressively high $\varepsilon^{\prime}{ }_{\mathrm{r}}$, as listed in Table S1. The highest $\varepsilon_{\mathrm{r}}^{\prime}$ values at $1 \mathrm{kHz}$ were for AE4/GO-F $(432 \pm 49)$ and $\mathrm{BE} 4 / \mathrm{GO}-\mathrm{F}(380 \pm 130)$, much higher than those for most polymer nanocomposites (normally below 50 at $1 \mathrm{kHz}$ ) for energy applications. ${ }^{63-65}$

Figure $6 \mathrm{~g}$, h shows that imaginary electric modulus $\left(M^{\prime \prime}\right)$ abruptly increased with $f$ higher than $10^{3} \mathrm{~Hz}$. For the Asamples with $20 \%\left[\mathrm{C}_{2} \mathrm{mim}\right][\mathrm{OAc}]$, a well-defined peak evolved, indicating relaxation processes with a distribution of relaxation times (i.e., viscoelastic relaxation or dipolar relaxation). ${ }^{66}$ Compared with AE2-F, AE2/GO-F and AE2/ rGO-F displayed a more intensive peak at lower $f$. In this regard, inclusion of $\mathrm{GO}$ or rGO decreased biopolymer chain mobility, making ions and associated dipoles less mobile. In contrast, for a higher $\left[\mathrm{C}_{2} \mathrm{mim}\right][\mathrm{OAc}]$ content, the peak shifts to a higher $f$ as the IL facilitates biopolymer chain movement and increased mobility of ions and associated dipoles. Compared with AE4-F, AE4/rGO showed the $M^{\prime \prime}$ peak at a slightly lower $f$, whereas for AE4/GO-F, $M^{\prime \prime}$ kept increasing up to the highest $f$ tested. This could be linked to the effect of the nanofiller on the availability of free, mobile ions, and dipoles in the samples, as already proved in the discussion on $\sigma_{\mathrm{dc}}$.

All of the B-samples with $20 \%\left[\mathrm{C}_{2} \mathrm{mim}\right][\mathrm{OAc}]$ displayed a relaxation peak in $M^{\prime \prime}$ at similar $f$. In comparison, for BE4-F, the peak moved to higher $f$. Excess $\left[\mathrm{C}_{2}\right.$ mim] [OAc] disturbs $\mathrm{PEC}$, resulting in increased chain, ionic, and dipole mobilities. BE4/rGO-F displayed the $M^{\prime \prime}$ peak at a lower $f$, whereas, for $\mathrm{BE} 4 / \mathrm{GO}-\mathrm{F}$, the peak further moved to higher $f$, as the case for AE4/GO-F.

Mechanical Properties. The Young's modulus $(E)$, tensile strength $\left(\sigma_{\mathrm{t}}\right)$, and elongation at break $\left(\varepsilon_{\mathrm{b}}\right)$ of the different samples were calculated; see Figure 7 . Overall, the $\left[\mathrm{C}_{2} \mathrm{mim}\right]$ [OAc] content influenced the tensile properties more than GO or rGO addition, perhaps unsurprising given the relatively low loading at 0.75 wt $\%$. The samples with 20 wt \% $\left[\mathrm{C}_{2} \mathrm{mim}\right][\mathrm{OAc}]$ had notably higher $E$ and $\sigma_{\mathrm{t}}$ but lower $\varepsilon_{\mathrm{b}}$ than those with $40 \mathrm{wt} \%\left[\mathrm{C}_{2} \mathrm{mim}\right][\mathrm{OAc}]$ content. The highest $\sigma_{\mathrm{t}}$ was displayed by the B-matrix with 20 wt $\%$ [ $\left.\mathrm{C}_{2} \mathrm{mim}\right][\mathrm{OAc}]$ (e.g., for BE2-F, $39.1 \pm 2.6 \mathrm{MPa}$ ), which could be ascribed to PEC between the two biopolymers. At a higher IL content, biopolymer chain interactions and entanglements are reduced, resulting in diminished mechanical properties. For the B-matrix with 40 wt $\%\left[\mathrm{C}_{2} \mathrm{mim}\right][\mathrm{OAc}]$, addition of $\mathrm{GO}$ or rGO further decreased $E$ and $\sigma_{t}$, suggesting possibly weakened PEC. For either A- or B-matrix with 20 wt $\%$ [ $\left.\mathrm{C}_{2} \mathrm{mim}\right]$ [OAc], addition of $\mathrm{rGO}$ only led to an increase in $E$ (for $\mathrm{AE} 2 / \mathrm{rGO}, 1011 \pm 68$ $\mathrm{MPa}$; and for $\mathrm{BE} 2 / \mathrm{rGO}, 1018 \pm 100 \mathrm{MPa}$ ), while addition of $\mathrm{GO}$ resulted in decreases in $\sigma_{\mathrm{t}}$ and $\varepsilon_{\mathrm{b}}$ for AE2/GO-F. Previously, we reported that addition of GO or rGO to both A$\mathrm{F}$ and $\mathrm{B}-\mathrm{F}$ yielded increased mechanical properties. ${ }^{36}$ In this instance, the presence of the IL significantly reduces the interactions between $\mathrm{GO}$ or $\mathrm{rGO}$ and the biopolymer matrix. The greatest effect was observed for the A-samples with $40 \mathrm{wt}$ $\%\left[\mathrm{C}_{2} \mathrm{mim}\right][\mathrm{OAc}]$ content, which showed the lowest $E$ and $\sigma_{\mathrm{t}}$ (e.g., for AE4-F, $E=101 \pm 15 \mathrm{MPa}, \sigma_{\mathrm{t}}=11.6 \pm 1.3 \mathrm{MPa}$ )

Contact Angle. The surface hydrophilicity of films is represented by contact angle values at $0 \mathrm{~s}$ and $60 \mathrm{~s}\left(\theta_{\mathrm{c} 0 \mathrm{~s}}\right.$ and $\left.\theta_{\mathrm{c} 60 \mathrm{~s}}\right)$, as shown in Figure 8. Compared with A-F $\left(\theta_{\mathrm{c} 0 \mathrm{~s}}=90 \pm\right.$ $5^{\circ}$ and $\left.\theta_{\mathrm{c} 60 \mathrm{~s}}=68 \pm 5^{\circ}\right),{ }^{26}$ AE2-F had decreased surface hydrophilicity with $\theta_{\mathrm{c} 0 \mathrm{~s}}=100 \pm 7^{\circ}$ and $\theta_{\mathrm{c} 60 \mathrm{~s}}=71 \pm 10^{\circ}$, i.e., the surface of this sample became more hydrophobic and not expected given the high hydrophilicity of ILs. A previous study $^{8}$ reported the significantly lower hydrophilicity of thermoplastic starch plasticized by 1-butyl-3-methylimidazo- 


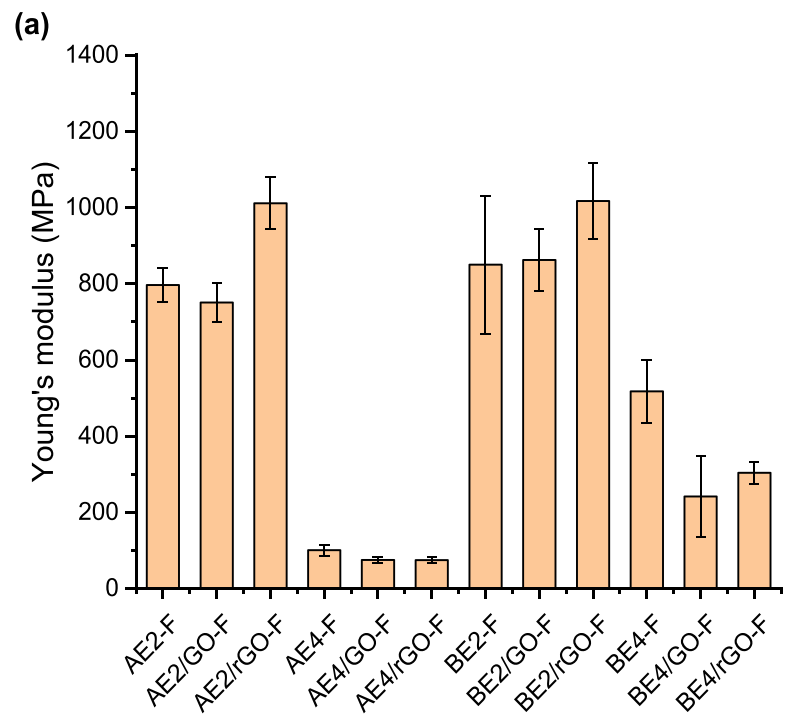

(b)

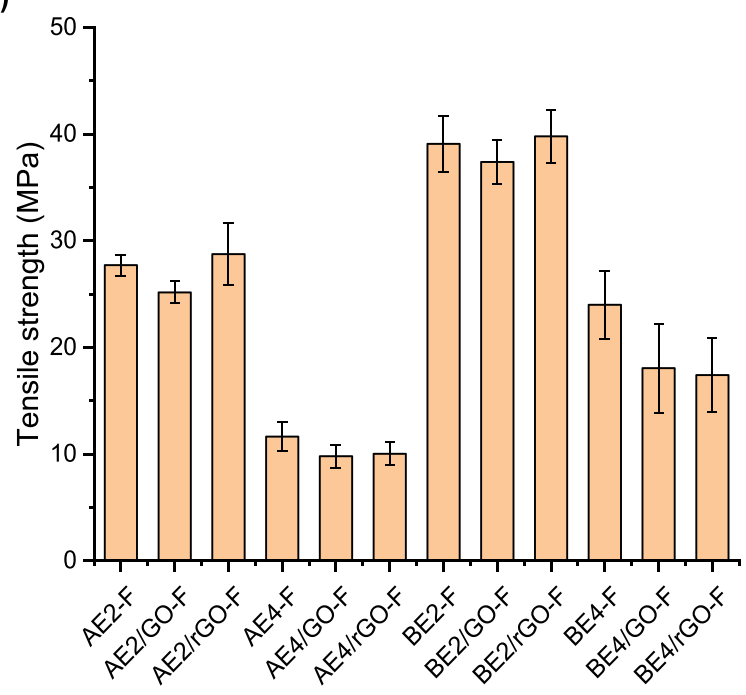

(c)

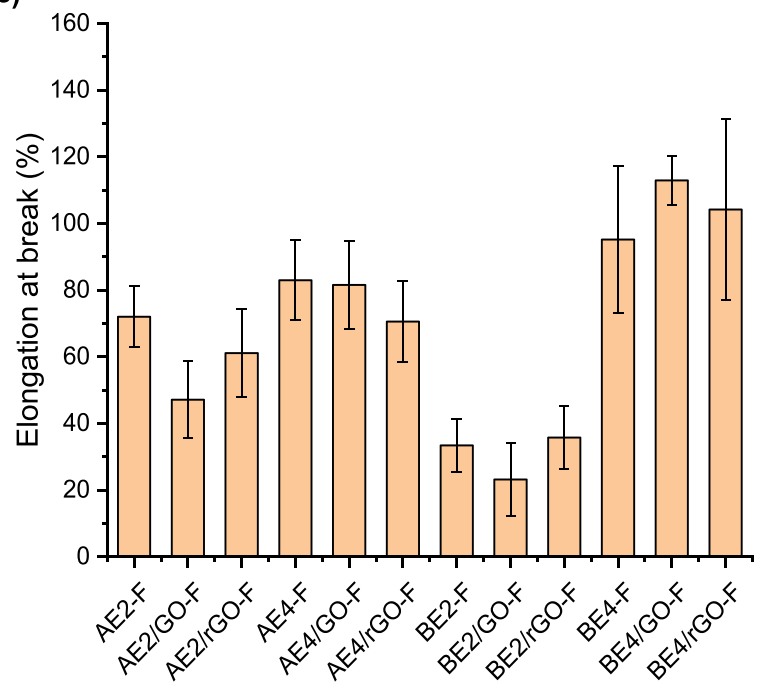

Figure 7. (a) Young's modulus, (b) tensile strength, and (c) elongation at break of the different biopolymer and composite films. The error bars represent standard deviations.

lium chloride $\left(\left[\mathrm{C}_{4} \mathrm{mim}\right] \mathrm{Cl}\right)$ compared to glycerol. In this work, we speculate that the strong hydrogen-bonding interaction

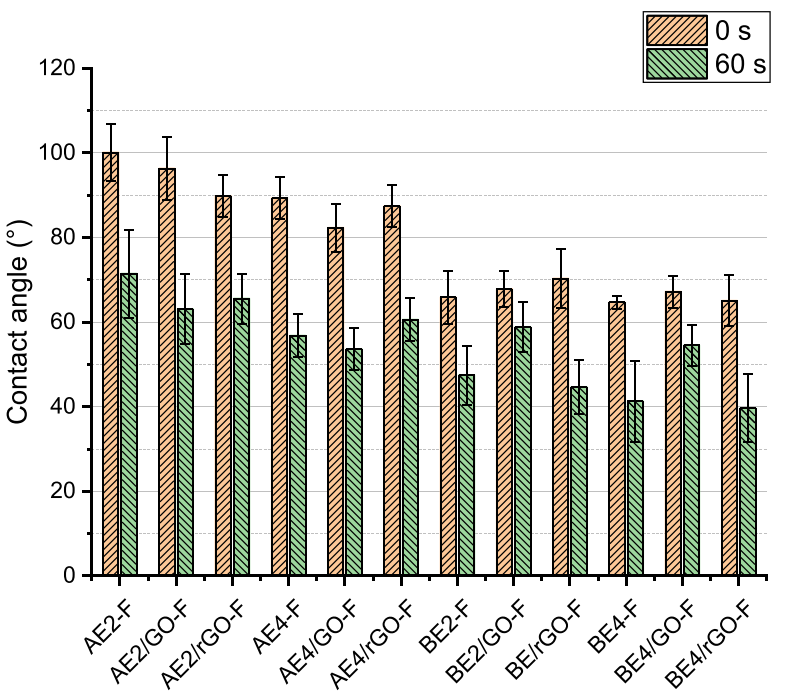

Figure 8. Contact angle values for the different biopolymer and bionanocomposite films at 0 and $60 \mathrm{~s}$. The error bars represent standard deviations.

between chitosan and $\left[\mathrm{C}_{2} \mathrm{mim}\right][\mathrm{OAc}]$ reduces the availability of the hydroxyl groups from chitosan or the IL ions to bind with water molecules, especially at the immediate start of the sessile measurement. The inclusion of GO or rGO increased the surface hydrophilicity, with the effect being greater with rGO. The values of $\theta_{c 0 s}$ and $\theta_{c 60 s}$ for AE2/rGO-F were similar to those reported previously for A-F. ${ }^{26}$ Therefore, GO or rGO may disrupt the hydrogen bonding between chitosan chains, making more hydroxyl groups available to interact with water.

Compared to those for AE2-F, the $\theta_{c 0 s}$ and $\theta_{c 60 s}$ values for AE4-F were reduced. The increased surface hydrophilicity could be due to excess $\left[\mathrm{C}_{2} \mathrm{mim}\right][\mathrm{OAc}]$ in the composite system, which is free to bind with water molecules. The addition of GO slightly reduced $\theta_{\mathrm{c} 0 \mathrm{~s}}$ and $\theta_{\mathrm{c} 60 \mathrm{~s}}$, while rGO led to slightly increased $\theta_{\mathrm{c} 60 \mathrm{~s}}$, a behavior related to the difference in hydrophilicity/hydrophobicity of the surfaces of GO and rGO, the latter more hydrophobic.

For B-F, $\theta_{c 0 s}=71 \pm 6^{\circ}$ and $\theta_{c 60 s}=60 \pm 5^{\circ} .^{26}$ The presence of the CMC sodium salt obviously contributed to increased surface hydrophilicity of the matrix, most likely due to the carboxyl groups and $\mathrm{Na}^{+}$ions. When plasticized by $\left[\mathrm{C}_{2} \mathrm{mim}\right]$ [OAc], BE-F exhibited lower $\theta_{c 0 s}$ and $\theta_{c 60 s}$ values $(66 \pm 6$ and $47 \pm 7)$ than those of B-F. Further addition of GO led to increased $\theta_{c 60 s}$, while the effect of rGO was insignificant. In this regard, the interaction between $\mathrm{GO}$ and the $\mathrm{IL}$ may reduce the interaction of IL ions with water. Compared with AE2-F, AE4F exhibited further reduced $\theta_{c 60 s}$. To this matrix, the addition of rGO was not effective, whereas GO notably increased $\theta_{\text {c60 s }}$, which, again, can be ascribed to the interaction between GO and the IL.

\section{CONCLUSIONS}

There are several interactions among different components in chitosan and chitosan/CMC polyelectrolyte complexed bionanocomposites, as summarized below:

(1) GO and rGO were effectively dispersed in both matrices by thermomechanical mixing. However, the influence of $\mathrm{GO} / \mathrm{rGO}$ on the structure and properties of the bionanocomposites is largely dependent on the $\left[\mathrm{C}_{2} \mathrm{mim}\right][\mathrm{OAc}]$ content. 
(2) $\left[\mathrm{C}_{2} \mathrm{mim}\right][\mathrm{OAc}]$ acts as a plasticizer and had the dominant effect on the structure and properties of the bionanocomposites. The presence of the IL increased the mobility of the biopolymer chains as well as IL ions and associated dipoles, reducing chain interactions and entanglements, biopolymer crystallinity, and thermal stability. This resulted in the bionanocomposites having higher ionic conductivity, shorter electrical relaxation times, and reduced stiffness and strength, but greater ductility.

(3) PEC between the biopolymers resulted in reduced biopolymer chain mobility, higher mechanical strength, rigidity, and thermal stability but lower ion conductivity. However, PEC was strongly affected by the efficacy of IL plasticization and inclusion of $\mathrm{GO} / \mathrm{rGO}$.

Thus, this study shows that the structure and properties of bionanocomposites are not just determined by the surface chemistry of $\mathrm{GO} / \mathrm{rGO}$ but can also be influenced by multiple interactions involving plasticizers such as ILs and additional biopolymers. The new information obtained here could guide the rational design of such materials with competitive properties.

\section{EXPERIMENTAL SECTION}

Materials. Chitosan (poly $(\beta-(1,4)$-D-glucosamine $))$, derived from crab shells, with a weight-average molecular mass $\left(M_{\mathrm{w}}\right)$ of about $150000 \mathrm{~g} \cdot \mathrm{mol}^{-1}$, a degree of deacetylation (DD) of $>90 \%$, and a viscosity of about $100 \mathrm{mPa} \cdot \mathrm{s}$ (i.e., $1 \%$ solution in $1 \%$ acetic acid at $25{ }^{\circ} \mathrm{C}$ ), was purchased from Shanghai Ryon Biological Technology Co., Ltd. (China). The characteristics of this chitosan are shown in our previous study. ${ }^{41}$ CMC sodium, with an $M_{w}$ value of $90000 \mathrm{~g} \cdot \mathrm{mol}^{-1}$, a degree of substitution (DS) of 0.7 , and a viscosity of 50-100 $\mathrm{mPa} \cdot \mathrm{s}$ (Brookfield, $2 \%$ solution, at $25^{\circ} \mathrm{C}$ ), was purchased from Shanghai Macklin Biochemical Co., Ltd. (China). This CMC was characterized previously. ${ }^{26}$ GO (aqueous acid paste with $25 \% \mathrm{GO}, 74 \%$ water, and $1-1.5 \% \mathrm{HCl}$ ) was purchased from Abalonyx AS (Norway). Hydrazine hydrate solution (78-82\% iodometric, Honeywell Fluka) and ammonia solution (35\%, AR, $d=0.88$ ) were supplied by Fisher Scientific U.K. Ltd.; $\left[\mathrm{C}_{2} \mathrm{mim}\right][\mathrm{OAc}](\geq 95.0 \%)$ by Sigma-Aldrich Company Ltd. (U.K.); and formic acid (98\% w/w AR) and $\mathrm{NaBr}$ (pure) were supplied by Scientific Laboratory Supplies Ltd. (U.K.). Deionized water was used for all experiments.

Synthesis of Reduced Graphene Oxide ( $\mathrm{rGO}$ ). rGO was synthesized from GO as described previously. ${ }^{36}$ Briefly, a mixture of $40 \mathrm{~g}$ of the GO paste ( $25 \mathrm{wt} \%$ concentration, used as received), $150 \mathrm{~mL}$ of distilled water, $25 \mathrm{~mL}$ of the hydrazine hydrate solution, and $25 \mathrm{~mL}$ of the ammonia solution (both used as received) in a round-bottom flask was heated at $90{ }^{\circ} \mathrm{C}$ for $4 \mathrm{~h}$ with magnetic stirring under reflux. After this reaction, this mixture was filtered and washed with water to reach neutral $\mathrm{pH}$, followed by drying in a vacuum oven. For the powder product obtained, the same procedure was performed once again to ensure adequate reaction.

Sample Preparation. Table 1 shows the formulations and codes of the different samples prepared in this work. In these codes, the prefix " $\mathrm{A}$ " represents chitosan alone as the matrix while " $\mathrm{B}$ " indicates chitosan/CMC as the matrix. The suffix " $\mathrm{F}$ " indicates the processed samples as films. The $\left[\mathrm{C}_{2} \mathrm{mim}\right][\mathrm{OAc}]$ content is represented by the letter "E" followed by a number, for example, "E2" for $20 \mathrm{wt} \%\left[\mathrm{C}_{2} \mathrm{mim}\right][\mathrm{OAc}]$. The samples
Table 1. Sample Codes and Compositions Used in This Study (Represented as Portions by Weight)

\begin{tabular}{lcccccc}
\multicolumn{1}{c}{ sample } & chitosan & CMC & $\begin{array}{c}{\left[\mathrm{C}_{2} \text { mim }\right]} \\
{[\mathrm{OAc}]}\end{array}$ & GO & rGO & $\begin{array}{c}2 \text { M formic } \\
\text { acid } \\
\text { solution }\end{array}$ \\
AE2-F & 100 & & 20 & & & 261 \\
AE2/GO-F & 100 & & 20 & 0.75 & & 261 \\
AE2/rGO-F & 100 & & 20 & & 0.75 & 261 \\
AE4-F & 100 & & 40 & & & 261 \\
AE4/GO-F & 100 & & 40 & 0.75 & & 261 \\
AE4/rGO-F & 100 & & 40 & & 0.75 & 261 \\
BE2-F & 50 & 50 & 20 & & & 261 \\
BE2/GO-F & 50 & 50 & 20 & 0.75 & & 261 \\
BE2/rGO-F & 50 & 50 & 20 & & 0.75 & 261 \\
BE4-F & 50 & 50 & 40 & & & 261 \\
BE4/GO-F & 50 & 50 & 40 & 0.75 & & 261 \\
BE4/rGO-F & 50 & 50 & 40 & & 0.75 & 261 \\
\hline
\end{tabular}

were prepared by preblending, thermomechanical kneading, hot-pressing, and then conditioning, as described previously, ${ }^{26}$ except that the GO or $\mathrm{rGO}$ and $\left[\mathrm{C}_{2} \mathrm{mim}\right][\mathrm{OAc}]$ were added during the preblending stage.

Characterization. Scanning electron microscopy (SEM) was performed using a ZEISS SIGMA field emission scanning electron microscope at $6 \mathrm{kV}$. The samples were prepared by cryo-fracturing films under liquid nitrogen cooling and sputtercoated with gold/palladium.

Scanning transmission electron microscopy (STEM) was conducted using a field emission gun Talos F200X transmission electron microscope operating at $200 \mathrm{kV}$, in which both STEM bright-field (BF) and high-angle annular dark-field (HAADF) images were acquired simultaneously. Sample ribbons, about $60 \mathrm{~nm}$ thick, were sectioned from epoxyembedded sample blocks and subsequently transferred on to 200-mesh copper grids coated with holey carbon films. No liquid solution was involved, to avoid potential damage to the samples.

X-ray diffractograms were acquired using a PANalytical Empyrean X-ray diffractometer with a Co target $(\mathrm{K} \alpha=$ $1.790307 \AA$ ) and a beam slit of $10 \mathrm{~mm}$ at $40 \mathrm{kV}$ and $40 \mathrm{~mA}$. The samples were scanned over an angular range $(2 \theta)$ of $6-$ $40^{\circ}$ with a step size of $0.0263^{\circ}$ and a scan rate of $2.16 \mathrm{~s} \cdot \mathrm{step}^{-1}$.

Fourier transform infrared (FTIR) spectra were collected using a Bruker TENSOR 27 FTIR spectrometer with an attenuated total reflection (ATR) accessory with 32 scans for each sample over a range of $4000-500 \mathrm{~cm}^{-1}$ at room temperature (RT).

Thermogravimetric analysis (TGA) was undertaken using a Mettler Toledo TGA apparatus over a temperature range of $30-700{ }^{\circ} \mathrm{C}$ at $10 \mathrm{~K} \cdot \mathrm{min}^{-1}$ under nitrogen.

Dynamic mechanical thermal analysis (DMTA) was performed using a Tritec 2000 DMA (Triton Technology Ltd., U.K.) in the dual cantilever mode with a sample length of $5 \mathrm{~mm}$ at a displacement of $0.01 \mathrm{~mm}$. Temperature scans were performed from $-100{ }^{\circ} \mathrm{C}$ to $180{ }^{\circ} \mathrm{C}$ at $2 \mathrm{~K} \cdot \mathrm{min}^{-1}$ and $1 \mathrm{~Hz}$. Frequency scans were conducted from 0.01 to $20 \mathrm{~Hz}$ at RT.

Electrical impedance spectroscopy (EIS) was performed using a Princeton Applied Research PARSTAT MC (PMC) multichannel potentiostat (Ametek Scientific Instrument) with a PMC-2000 card and a two-point probe. The two surfaces of samples were painted with carbon conductive grease (No. 8481, MG Chemicals, Canada $)$ in designated areas $(24 \times 24$ $\left.\mathrm{mm}^{2}\right)$. All tests were performed in triplicate. The real $\left(Z^{\prime}\right)$ and 
imaginary $\left(Z^{\prime \prime}\right)$ parts of impedance were acquired with a frequency $(f)$ range of $1-10^{6} \mathrm{~Hz}$. The AC conductivity (admittance) $(\sigma)$, the real part of relative permittivity $\left(\varepsilon_{\mathrm{r}}^{\prime}\right)$, and the imaginary part of electric modulus $\left(M^{\prime \prime}\right)$ were calculated using the following equations ${ }^{60,67,68}$

$$
\begin{aligned}
& \sigma=\frac{Z^{\prime}}{Z^{\prime 2}+Z^{\prime \prime}} \times \frac{t}{A} \\
& \varepsilon_{\mathrm{r}}^{\prime}=\frac{-Z^{\prime \prime}}{Z^{\prime 2}+Z^{\prime \prime 2}} \times \frac{t}{\omega A \varepsilon_{0}} \\
& M^{\prime \prime}=\frac{\varepsilon^{\prime \prime}}{\varepsilon^{\prime 2}+\varepsilon^{\prime \prime 2}}
\end{aligned}
$$

where $\omega$ is the angular frequency $(=2 \pi f), \varepsilon_{0}$ is the permittivity of free space $\left(\approx 8.854 \times 10^{-12} \mathrm{~F} \cdot \mathrm{m}^{-1}\right), A$ is the tested area of the sample $\left(\mathrm{m}^{2}\right)$, and $t$ is the sample thickness $(\mathrm{m})$.

The bulk resistance $\left(R_{\mathrm{b}}\right)$ was determined from the Nyquist plots of impedance $\left(Z^{\prime \prime}\right.$ vs $\left.Z^{\prime}\right)$ from the points where the semicircle and the straight line meet. Then, the conductivity $\left(\sigma_{\mathrm{dc}}\right)$ can be calculated using eq $4^{60,66}$

$$
\sigma_{\mathrm{dc}}=\frac{t}{R_{\mathrm{b}} \times A}
$$

Tensile testing (at least seven replicates) was performed using an Instron 3367 universal testing machine with a $1 \mathrm{kN}$ load cell and a crosshead speed of $3 \mathrm{~mm} / \mathrm{min}$. As the specimens were in the form of thin sheets, specimen extension was measured by grip separation, as suggested by ASTM Standard D882.

Contact angle $\left(\theta_{\mathrm{c}}\right)$ data were obtained from sessile tests at RT based on the Young-Laplace equation using an Attension Theta Lite instrument (Biolin Scientific, U.K.).

\section{ASSOCIATED CONTENT}

\section{SI Supporting Information}

The Supporting Information is available free of charge at https://pubs.acs.org/doi/10.1021/acsomega.0c02418.

FTIR spectrum and TGA result of $\left[\mathrm{C}_{2} \mathrm{mim}\right][\mathrm{OAc}]$ (Figure S2); SEM images (Figure S1), representative stress-strain curves (Figure S3), Shore D hardness (Figure S4), and electrochemical results (Table S1) of the different biopolymer films; and notes to figures (PDF)

\section{AUTHOR INFORMATION}

\section{Corresponding Authors}

Fengwei Xie - International Institute for Nanocomposites Manufacturing (IINM), WMG, University of Warwick, Coventry CV4 7AL, United Kingdom; School of Chemical Engineering, The University of Queensland, Brisbane, Qld 4072,

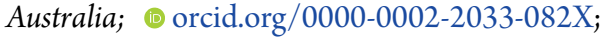
Email: d.xie.2@warwick.ac.uk, fwhsieh@gmail.com

Tony McNally - International Institute for Nanocomposites Manufacturing (IINM), WMG, University of Warwick, Coventry CV4 7AL, United Kingdom; orcid.org/00000001-5436-4211; Email: t.mcnally@warwick.ac.uk

\section{Authors}

Pei Chen - College of Food Science, South China Agricultural University, Guangzhou, Guangdong 510642, China; International Institute for Nanocomposites Manufacturing
(IINM), WMG, University of Warwick, Coventry CV4 7AL, United Kingdom

Fengzai Tang - WMG, University of Warwick, Coventry CV4 $7 A L$, United Kingdom

Complete contact information is available at:

https://pubs.acs.org/10.1021/acsomega.0c02418

\section{Author Contributions}

All authors have given approval to the final version of the manuscript. F.X. led the research.

\section{Notes}

The authors declare no competing financial interest.

\section{ACKNOWLEDGMENTS}

The authors acknowledge funding from the European Union's Horizon 2020 research and innovation program under the Marie Skłodowska-Curie grant agreement no. 798225. P.C. acknowledges the financial support from the China Scholarship Council (CSC) for her visiting position and thanks IINM, WMG, University of Warwick, U.K., for hosting her research visit. F.X. also acknowledges support from the Guangxi Key Laboratory for Polysaccharide Materials and Modification, Guangxi University for Nationalities, China (grant no. GXPSMM18ZD-02).

\section{ABBREVIATIONS USED}

CMC, carboxymethyl cellulose; GO, graphene oxide; rGO, reduced graphene oxide; $\mathrm{PEC}$, polyelectrolyte complexation; $\mathrm{IL}$, ionic liquid; $\left[\mathrm{C}_{2} \mathrm{mim}\right][\mathrm{OAc}]$, 1-ethyl-3-methylimidazolium acetate; $T_{\mathrm{d}}$, thermal decomposition temperature at maximum weight loss rate; $\tan \delta$, loss tangent; $T_{\beta}$, peak temperature of $\beta$ transition; $T_{\alpha}$, peak temperature of $\alpha$-transition; $\theta_{\text {c0s }}$, contact angle at $0 \mathrm{~s} ; \theta_{\mathrm{c} 60 \mathrm{~s}}$, contact angle at $60 \mathrm{~s}$

\section{REFERENCES}

(1) Song, J.; Chen, C.; Zhu, S.; Zhu, M.; Dai, J.; Ray, U.; Li, Y.; Kuang, Y.; Li, Y.; Quispe, N.; Yao, Y.; Gong, A.; Leiste, U. H.; Bruck, H. A.; Zhu, J. Y.; Vellore, A.; Li, H.; Minus, M. L.; Jia, Z.; Martini, A.; Li, T.; Hu, L. Processing bulk natural wood into a high-performance structural material. Nature 2018, 554, 224.

(2) Frey, M.; Widner, D.; Segmehl, J. S.; Casdorff, K.; Keplinger, T.; Burgert, I. Delignified and Densified Cellulose Bulk Materials with Excellent Tensile Properties for Sustainable Engineering. ACS Appl. Mater. Interfaces 2018, 10, 5030-5037.

(3) Fang, Z.; Li, B.; Liu, Y.; Zhu, J.; Li, G.; Hou, G.; Zhou, J.; Qiu, X. Critical Role of Degree of Polymerization of Cellulose in SuperStrong Nanocellulose Films. Matter 2020, 2, 1000-1014.

(4) Xie, F.; Flanagan, B. M.; Li, M.; Sangwan, P.; Truss, R. W.; Halley, P. J.; Strounina, E. V.; Whittaker, A. K.; Gidley, M. J.; Dean, K. M.; Shamshina, J. L.; Rogers, R. D.; McNally, T. Characteristics of starch-based films plasticised by glycerol and by the ionic liquid 1ethyl-3-methylimidazolium acetate: a comparative study. Carbohydr. Polym. 2014, 111, 841-848.

(5) Xie, F.; Flanagan, B. M.; Li, M.; Truss, R. W.; Halley, P. J.; Gidley, M. J.; McNally, T.; Shamshina, J. L.; Rogers, R. D. Characteristics of starch-based films with different amylose contents plasticised by 1-ethyl-3-methylimidazolium acetate. Carbohydr. Polym. 2015, 122, 160-168.

(6) Zhang, B.; Xie, F.; Zhang, T.; Chen, L.; Li, X.; Truss, R. W.; Halley, P. J.; Shamshina, J. L.; McNally, T.; Rogers, R. D. Different characteristic effects of ageing on starch-based films plasticised by 1ethyl-3-methylimidazolium acetate and by glycerol. Carbohydr. Polym. 2016, 146, 67-79.

(7) Zhang, B.; Xie, F.; Shamshina, J. L.; Rogers, R. D.; McNally, T.; Wang, D. K.; Halley, P. J.; Truss, R. W.; Zhao, S.; Chen, L. Facile 
Preparation of Starch-Based Electroconductive Films with Ionic Liquid. ACS Sustainable Chem. Eng. 2017, 5, 5457-5467.

(8) Sankri, A.; Arhaliass, A.; Dez, I.; Gaumont, A. C.; Grohens, Y.; Lourdin, D.; Pillin, I.; Rolland-Sabaté, A.; Leroy, E. Thermoplastic starch plasticized by an ionic liquid. Carbohydr. Polym. 2010, 82, 256-263.

(9) Leroy, E.; Jacquet, P.; Coativy, G.; Reguerre, Al.; Lourdin, D. Compatibilization of starch-zein melt processed blends by an ionic liquid used as plasticizer. Carbohydr. Polym. 2012, 89, 955-963.

(10) Colomines, G.; Decaen, P.; Lourdin, D.; Leroy, E. Biofriendly ionic liquids for starch plasticization: a screening approach. RSC $A d v$. 2016, 6, 90331-90337.

(11) Decaen, P.; Rolland-Sabaté, A.; Guilois, S.; Jury, V.; Allanic, N.; Colomines, G.; Lourdin, D.; Leroy, E. Choline chloride vs choline ionic liquids for starch thermoplasticization. Carbohydr. Polym. 2017, 177, 424-432.

(12) Ren, F.; Wang, J.; Xie, F.; Zan, K.; Wang, S.; Wang, S. Applications of ionic liquids in starch chemistry: a review. Green Chem. 2020, 22, 2162-2183.

(13) Ning, W.; Zhang, X.; Wang, X.; Liu, H. Ionic liquids modified montmorillonite/thermoplastic starch nanocomposites as ionic conducting biopolymer. Macromol. Res. 2009, 17, 285-288.

(14) Ning, W.; Zhang, X.; Liu, H.; He, B. 1-Allyl-3-methylimidazolium chloride plasticized-corn starch as solid biopolymer electrolytes. Carbohydr. Polym. 2009, 76, 482-484.

(15) Ning, W.; Zhang, X.; Liu, H.; Han, N. Ionically conducting polymers based on ionic liquid-plasticized starch containing lithium chloride. Polym. Polym. Compos. 2010, 18, 53-58.

(16) Ramesh, S.; Liew, C.-W.; Arof, A. K. Ion conducting corn starch biopolymer electrolytes doped with ionic liquid 1-butyl-3-methylimidazolium hexafluorophosphate. J. Non-Cryst. Solids 2011, 357, 3654-3660.

(17) Ramesh, S.; Shanti, R.; Morris, E.; Durairaj, R. Utilisation of Corn Starch in Production of 'green' Polymer Electrolytes. Mater. Res. Innovations 2011, 15, s13-s8.

(18) Ramesh, S.; Shanti, R.; Morris, E. Studies on the thermal behavior of CS:LiTFSI:[Amim] $\mathrm{Cl}$ polymer electrolytes exerted by different [Amim] Cl content. Solid State Sci. 2012, 14, 182-186.

(19) Liew, C.-W.; Ramesh, S. Electrical, structural, thermal and electrochemical properties of corn starch-based biopolymer electrolytes. Carbohydr. Polym. 2015, 124, 222-228.

(20) Liew, C.-W.; Ramesh, S.; Ramesh, K.; Arof, A. Preparation and characterization of lithium ion conducting ionic liquid-based biodegradable corn starch polymer electrolytes. J. Solid State Electrochem. 2012, 16, 1869-1875.

(21) Wang, H.; Gurau, G.; Rogers, R. D. Ionic liquid processing of cellulose. Chem. Soc. Rev. 2012, 41, 1519-1537.

(22) Li, Z.; Ramay, H. R.; Hauch, K. D.; Xiao, D.; Zhang, M. Chitosan-alginate hybrid scaffolds for bone tissue engineering. Biomaterials 2005, 26, 3919-3928.

(23) Wei, C.; Zhu, X.; Peng, H.; Chen, J.; Zhang, F.; Zhao, Q. Facile Preparation of Lignin-Based Underwater Adhesives with Improved Performances. ACS Sustainable Chem. Eng. 2019, 7, 4508-4514.

(24) Meng, L.; Xie, F.; Zhang, B.; Wang, D. K.; Yu, L. Natural Biopolymer Alloys with Superior Mechanical Properties. ACS Sustainable Chem. Eng. 2019, 7, 2792-2802.

(25) Basu, S.; Plucinski, A.; Catchmark, J. M. Sustainable barrier materials based on polysaccharide polyelectrolyte complexes. Green Chem. 2017, 19, 4080-4092.

(26) Chen, P.; Xie, F.; Tang, F.; McNally, T. Thermomechanicalinduced polyelectrolyte complexation between chitosan and carboxymethyl cellulose enabling unexpected hydrolytic stability. Compos. Sci. Technol. 2020, 189, No. 108031.

(27) Iwasaki, N.; Yamane, S.-T.; Majima, T.; Kasahara, Y.; Minami, A.; Harada, K.; Nonaka, S.; Maekawa, N.; Tamura, H.; Tokura, S.; Shiono, M.; Monde, K.; Nishimura, S.-I. Feasibility of Polysaccharide Hybrid Materials for Scaffolds in Cartilage Tissue Engineering: Evaluation of Chondrocyte Adhesion to Polyion Complex Fibers
Prepared from Alginate and Chitosan. Biomacromolecules 2004, 5, $828-833$.

(28) Yang, X.; Tu, Y.; Li, L.; Shang, S.; Tao, X.-m. Well-Dispersed Chitosan/Graphene Oxide Nanocomposites. ACS Appl. Mater. Interfaces 2010, 2, 1707-1713.

(29) Kuilla, T.; Bhadra, S.; Yao, D.; Kim, N. H.; Bose, S.; Lee, J. H. Recent advances in graphene based polymer composites. Prog. Polym. Sci. 2010, 35, 1350-1375.

(30) Chen, J.; Peng, H.; Wang, X.; Shao, F.; Yuan, Z.; Han, H. Graphene oxide exhibits broad-spectrum antimicrobial activity against bacterial phytopathogens and fungal conidia by intertwining and membrane perturbation. Nanoscale 2014, 6, 1879-1889.

(31) Perreault, F.; de Faria, A. F.; Nejati, S.; Elimelech, M. Antimicrobial Properties of Graphene Oxide Nanosheets: Why Size Matters. ACS Nano 2015, 9, 7226-7236.

(32) Di Giulio, M.; Zappacosta, R.; Di Lodovico, S.; Di Campli, E.; Siani, G.; Fontana, A.; Cellini, L. Antimicrobial and Antibiofilm Efficacy of Graphene Oxide against Chronic Wound Microorganisms. Antimicrob. Agents Chemother. 2018, 62, e00547-18.

(33) Al-Jumaili, A.; Alancherry, S.; Bazaka, K.; Jacob, M. V. Review on the Antimicrobial Properties of Carbon Nanostructures. Materials 2017, 10, 1066.

(34) Han, D.; Yan, L.; Chen, W.; Li, W. Preparation of chitosan/ graphene oxide composite film with enhanced mechanical strength in the wet state. Carbohydr. Polym. 2011, 83, 653-658.

(35) Pan, Y.; Wu, T.; Bao, H.; Li, L. Green fabrication of chitosan films reinforced with parallel aligned graphene oxide. Carbohydr. Polym. 2011, 83, 1908-1915.

(36) Chen, P.; Xie, F.; Tang, F.; McNally, T. Structure and properties of thermomechanically processed chitosan/carboxymethyl cellulose/graphene oxide polyelectrolyte complexed bionanocomposites. Int. J. Biol. Macromol. 2020, 158, 420-429.

(37) Yang, J.; Pruvost, S.; Livi, S.; Duchet-Rumeau, J. Understanding of Versatile and Tunable Nanostructuration of Ionic Liquids on Fluorinated Copolymer. Macromolecules 2015, 48, 4581-4590.

(38) Remsing, R. C.; Swatloski, R. P.; Rogers, R. D.; Moyna, G. Mechanism of cellulose dissolution in the ionic liquid 1-n-butyl-3methylimidazolium chloride: A $13 \mathrm{C}$ and $35 / 37 \mathrm{Cl} \mathrm{NMR}$ relaxation study on model systems. Chem. Commun. 2006, 12, 1271-1273.

(39) Mateyawa, S.; Xie, D. F.; Truss, R. W.; Halley, P. J.; Nicholson, T. M.; Shamshina, J. L.; Rogers, R. D.; Boehm, M. W.; McNally, T. Effect of the ionic liquid 1-ethyl-3-methylimidazolium acetate on the phase transition of starch: Dissolution or gelatinization? Carbohydr. Polym. 2013, 94, 520-530.

(40) Zhang, B.; Xie, F.; Shamshina, J. L.; Rogers, R. D.; McNally, T.; Halley, P. J.; Truss, R. W.; Chen, L.; Zhao, S. Dissolution of Starch with Aqueous Ionic Liquid under Ambient Conditions. ACS Sustainable Chem. Eng. 2017, 5, 3737-3741.

(41) Chen, P.; Xie, F.; Tang, F.; McNally, T. Structure and properties of thermomechanically processed silk peptide and nanoclay filled chitosan. Nanocomposites 2019, Submitted.

(42) Layek, R. K.; Kundu, A.; Nandi, A. K. High-Performance Nanocomposites of Sodium Carboxymethylcellulose and Graphene Oxide. Macromol. Mater. Eng. 2013, 298, 1166-1175.

(43) Shahzadi, K.; Mohsin, I.; Wu, L.; Ge, X.; Jiang, Y.; Li, H.; Mu, X. Bio-Based Artificial Nacre with Excellent Mechanical and Barrier Properties Realized by a Facile In Situ Reduction and Cross-Linking Reaction. ACS Nano 2017, 11, 325-334.

(44) El Miri, N.; Abdelouahdi, K.; Barakat, A.; Zahouily, M.; Fihri, A.; Solhy, A.; El Achaby, M. Bio-nanocomposite films reinforced with cellulose nanocrystals: Rheology of film-forming solutions, transparency, water vapor barrier and tensile properties of films. Carbohydr. Polym. 2015, 129, 156-167.

(45) Rosca, C.; Popa, M. I.; Lisa, G.; Chitanu, G. C. Interaction of chitosan with natural or synthetic anionic polyelectrolytes. 1 . The chitosan-carboxymethylcellulose complex. Carbohydr. Polym. 2005, $62,35-41$.

(46) Lawrie, G.; Keen, I.; Drew, B.; Chandler-Temple, A.; Rintoul, L.; Fredericks, P.; Grøndahl, L. Interactions between Alginate and 
Chitosan Biopolymers Characterized Using FTIR and XPS. Biomacromolecules 2007, 8, 2533-2541.

(47) Pawlak, A.; Mucha, M. Thermogravimetric and FTIR studies of chitosan blends. Thermochim. Acta 2003, 396, 153-166.

(48) Chen, Z.; Mo, X.; He, C.; Wang, H. Intermolecular interactions in electrospun collagen-chitosan complex nanofibers. Carbohydr. Polym. 2008, 72, 410-418.

(49) Xie, D. F.; Martino, V. P.; Sangwan, P.; Way, C.; Cash, G. A.; Pollet, E.; Dean, K. M.; Halley, P. J.; Avérous, L. Elaboration and properties of plasticised chitosan-based exfoliated nano-biocomposites. Polymer 2013, 54, 3654-3662.

(50) Xie, F.; Luckman, P.; Milne, J.; McDonald, L.; Young, C.; Tu, C. Y.; Pasquale, T. D.; Faveere, R.; Halley, P. J. Thermoplastic starch: Current development and future trends. J. Renewable Mater. 2014, 2, 95-106.

(51) Martino, V.; Pollet, E.; Avérous, L. Novative biomaterials based on chitosan and poly $(\varepsilon$-caprolactone $)$ Elaboration of porous structures. J. Polym. Environ. 2011, 19, 819-826.

(52) Wendler, F.; Todi, L.-N.; Meister, F. Thermostability of imidazolium ionic liquids as direct solvents for cellulose. Thermochim. Acta 2012, 528, 76-84.

(53) Singh, S.; Varanasi, P.; Singh, P.; Adams, P. D.; Auer, M.; Simmons, B. A. Understanding the impact of ionic liquid pretreatment on cellulose and lignin via thermochemical analysis. Biomass Bioenergy 2013, 54, 276-283.

(54) Chen, Q.; Xu, A.; Li, Z.; Wang, J.; Zhang, S. Influence of anionic structure on the dissolution of chitosan in 1-butyl-3methylimidazolium-based ionic liquids. Green Chem. 2011, 13, $3446-3452$.

(55) Stankovich, S.; Dikin, D. A.; Piner, R. D.; Kohlhaas, K. A.; Kleinhammes, A.; Jia, Y.; Wu, Y.; Nguyen, S. T.; Ruoff, R. S. Synthesis of graphene-based nanosheets via chemical reduction of exfoliated graphite oxide. Carbon 2007, 45, 1558-1565.

(56) Quijada-Garrido, I.; Laterza, B.; Mazón-Arechederra, J. M.; Barrales-Rienda, J. M. Characteristic Features of Chitosan/Glycerol Blends Dynamics. Macromol. Chem. Phys. 2006, 207, 1742-1751.

(57) Quijada-Garrido, I.; Iglesias-González, V.; Mazón-Arechederra, J. M.; Barrales-Rienda, J. M. The role played by the interactions of small molecules with chitosan and their transition temperatures. Glass-forming liquids: 1,2,3-Propantriol (glycerol). Carbohydr. Polym. 2007, 68, 173-186.

(58) Bonanos, N.; Steele, B. C. H.; Butler, E. P. Applications of Impedance Spectroscopy. In Impedance Spectroscopy; Barsoukov, E.; Macdonald, J. R., Eds.; John Wiley \& Sons, Inc.: Hoboken, NJ, U.S.A., 2005; pp 205-537.

(59) Wang, X.; Chi, Y.; Mu, T. A review on the transport properties of ionic liquids. J. Mol. Liq. 2014, 193, 262-266.

(60) Osman, Z.; Ibrahim, Z. A.; Arof, A. K. Conductivity enhancement due to ion dissociation in plasticized chitosan based polymer electrolytes. Carbohydr. Polym. 2001, 44, 167-173.

(61) Khiar, A. S. A.; Puteh, R.; Arof, A. K. Conductivity studies of a chitosan-based polymer electrolyte. Phys. B 2006, 373, 23-27.

(62) Navaratnam, S.; Ramesh, K.; Ramesh, S.; Sanusi, A.; Basirun, W. J.; Arof, A. K. Transport mechanism studies of chitosan electrolyte systems. Electrochim. Acta 2015, 175, 68-73.

(63) Wang, Q.; Zhu, L. Polymer nanocomposites for electrical energy storage. J. Polym. Sci., Part B: Polym. Phys. 2011, 49, 14211429.

(64) Li, J.; Seok, S. I.; Chu, B.; Dogan, F.; Zhang, Q.; Wang, Q. Nanocomposites of Ferroelectric Polymers with TiO2 Nanoparticles Exhibiting Significantly Enhanced Electrical Energy Density. Adv. Mater. 2009, 21, 217-221.

(65) Barber, P.; Balasubramanian, S.; Anguchamy, Y.; Gong, S.; Wibowo, A.; Gao, H.; Ploehn, J. H.; Zur Loye, H.-C. Polymer Composite and Nanocomposite Dielectric Materials for Pulse Power Energy Storage. Materials 2009, 2, 1697-1733.

(66) Fadzallah, I. A.; Majid, S. R.; Careem, M. A.; Arof, A. K. Relaxation process in chitosan-oxalic acid solid polymer electrolytes. Ionics 2014, 20, 969-975.
(67) Bhatt, A. S.; Bhat, D. K.; Santosh, M. S.; Tai, C.-w. Chitosan/ $\mathrm{NiO}$ nanocomposites: a potential new dielectric material. J. Mater. Chem. 2011, 21, 13490-13497.

(68) Bowen, C. R.; Buschhorn, S.; Adamaki, V. Manufacture and characterization of conductor-insulator composites based on carbon nanotubes and thermally reduced graphene oxide. Pure Appl. Chem. 2014, 86, 765-774. 